\title{
1 Using a Homeogram to Detect Sleep in Free-living 2 Animals
}

3 Matt Gaidica ${ }^{1}$, Emily Studd ${ }^{2}$, Andrea E Wishart ${ }^{3}$, William Gonzalez ${ }^{1}$, Jeffrey E Lane ${ }^{3}$, Andrew

4 G McAdam $^{4}$, Stan Boutin ${ }^{2}$, Ben Dantzer ${ }^{1,5}$

5

$6 \quad{ }^{1}$ Department of Psychology, University of Michigan, Ann Arbor, MI, USA

$7 \quad{ }^{2}$ Department of Biological Sciences, University of Alberta, Edmonton, Alberta, Canada

$8{ }^{3}$ University of Saskatchewan, Saskatoon, Saskatchewan, Canada

$9{ }^{4}$ Department of Ecology and Evolutionary Biology, University of Colorado, Boulder, CO,

10 United States

$11{ }^{5}$ Department of Ecology and Evolutionary Biology, University of Michigan, Ann Arbor, MI, 12 USA

13

14 Running Headline (45 characters): Sleep from accelerometer data.

15

16 Keywords (8, alpha): accelerometer, actigraphy, behavior, physiology, sleep 


\section{Abstract}

1. Sleep is appreciated as a behavior critical to homeostasis, performance, and fitness. Yet, most of what we know about sleep comes from humans or controlled laboratory experiments. Assessing sleep in wild animals is challenging, as it is often hidden from view, and electrophysiological recordings that define sleep states are difficult to obtain. Accelerometers have offered great insight regarding gross movement, although ambiguous quiescent states like sleep have been largely ignored, limiting our understanding of this ubiquitous behavior.

2. We developed a broadly applicable sleep detection method called a homeogram that can be applied to accelerometer data collected from wild animals. We applied our methodology to detect sleep in free-ranging North American red squirrels (Tamiasciurus hudsonicus) in a region that experiences drastic seasonal shifts in light, temperature, and behavioral demands.

3. Our method characterized sleep in a manner consistent with limited existing studies and expanded those observations to provide evidence that red squirrels apply unique sleep strategies to cope with changing environments.

4. Applying our analytical strategy to accelerometer data from other species may open new possibilities to investigate sleep patterns for researchers studying wild animals. 


\section{Introduction}

36 Sleep is a ubiquitous animal behavior, such that—with rare exception-you know it when you

37 see it. Sleep is typified by a common body position, reduced responsiveness and mobility, rapid

38 reversibility, and a homeostatic rebound following deprivation (Ungurean et al., 2020). Sleep

39 also serves common functions; from reptiles to birds to mammals, it usually places an animal in

40 a temporary environment that reduces the risk of predation, decreases thermoregulatory and

41 metabolic demands, and optimizes access to shared resources (Anafi et al., 2019; Eban-

42 Rothschild et al., 2017). It is therefore unsurprising that studying sleep in unnatural or

43 augmented environments, such as the laboratory, eliminates many of the challenges and

44 pressures that influence sleep patterns on daily to evolutionary timescales (Rattenborg et al., 45 2017).

Tools and efforts to quantify sleep in the wild are few compared to those for the

47 laboratory (S. S. Campbell \& Tobler, 1984; Capellini, Barton, et al., 2008; Capellini, Nunn, et al., 2008; Gravett et al., 2017; Lesku et al., 2006, 2009; Massot et al., 2019; Rattenborg et al.,

49 2017; Stuber et al., 2015). Also, definitions of sleep are based upon neural-electrophysiology

50 data, making it an inherently invasive endeavour (Aulsebrook et al., 2016; Stickgold \& Walker,

51 2009). However, multi-axis accelerometers that quantify movement may have some utility in this

52 realm (Walch et al., 2019). After all, sleep and active behavior are usually antithetical

53 (Ruckebusch, 1972).

Efforts to characterize sleep using body motion have, arguably, been more vigorously

55 pursued towards applications related to human health, notably in the past decade due to wearable

56 consumer and medical electronics. This comprises an immense literature concerning

57 accelerometer-based sleep methods — some proprietary — that are tailored towards stereotyped, 
58 human sleep phenotypes (Altini \& Kinnunen, 2021; Ancoli-Israel et al., 2003; Cole et al., 1992;

59 Enomoto et al., 2009; Nakazaki et al., 2014; Paquet et al., 2007; Sadeh, 2011; Sadeh et al., 1994;

60 Sazonov et al., 2004; van Hees et al., 2018). However, underlying themes emerge in data

61 analysis techniques with regard to sleep. Ground-truthed data either from field observations or

62 laboratory animals can 'label' accelerometer data (i.e. behaviors visually identified in-sync with

63 sensor data) which strengthens the ability of algorithms — such as supervised machine learning-

64 to build models that directly map actigraphy features to behavior (H. A. Campbell et al., 2013;

65 Hammond et al., 2016; Tatler et al., 2018). Auxiliary sensors can also be used as features as well

66 (e.g., collar temperature), but these are often not standard in type, sampling frequency, precision,

67 or deployment method across disciplines. The resulting sleep algorithm may take the form of a

68 'black box' (Shuert et al., 2018), decision tree (Khanh et al., 2016), or resolve optimal

69 parameters to pre-defined equations (Chimienti et al., 2016; Patterson et al., 2019; R. P. Wilson

70 et al., 2006), which can be used with new, unlabelled data.

Despite relative success in characterizing sleep with labelled data, much of the data

72 coming from wild animals in quiescent states is unlabelled due to the difficulty of observing

73 animals in their natural sleep habitat (e.g., underground, in nests, or otherwise hidden in many

74 terrestrial animals) (Bedford et al., 2021; Brown et al., 2013). Furthermore, many species have

75 ill-defined sleep patterns, such that, despite a rich suite of seemingly similar tools for studying

76 sleep using accelerometry, few can be applied to wild animals since they rely on a priori

77 knowledge of sleep patterns or impose arbitrary, species-specific rules to their classification

78 procedure (Chimienti et al., 2016).

Here, we develop a robust, tunable, and physiologically consistent method of

80 characterizing sleep-wake patterns using accelerometry alone that we call a homeogram. Our 
81 approach uses an alternative method of reconciling unlabeled behavioral data by viewing it in

82 terms of the underlying biological processes that it represents. It is inspired by the two-process

83 model of sleep proposed by Borbély (1982) where sleep pressure is formed by the interaction of

84 a homeostatic process and circadian process. Our homeogram takes a Borbélyian approach to

85 modeling the overarching circadian rhythm based on a few rules and incorporates ubiquitous

86 features of sleep, such as the fact that it has both intensity and inertia, all while facilitating the

87 possibility of short sleep-wake episodes that occur day or night (Figure 1). The result is a sleep

88 estimation (as a probability) that can be binarized into asleep and awake states with minimal

89 code and language-independent mathematical transformations.

To test the effectiveness of our homeogram method to characterize sleep, we compiled

91 accelerometer data from five years of study of North American red squirrels (Tamiasciurus

92 hudsonicus) in Yukon, Canada. Red squirrels in this region are subject to high northern latitudes,

93 which have a daylight difference of over 13 hours between summer and winter, representing a

94 unique methodological and physiological challenge. Like many animals, despite a great deal of

95 understanding regarding red squirrel active behavior (Dantzer et al., 2013, 2016; Fisher et al.,

96 2019; Klugh, 1927; Studd et al., 2016, 2020), little is known about sleep patterns in general or

97 how they use sleep to cope with changing seasonal demands.

98 Below, we first describe how to construct a homeogram from raw acceleration data and

99 validate the algorithm using nest attendance (based on collar temperature). Next, we use the

100 binary form of the homeogram to generate sleep statistics and provide a gestalt view of how red

101 squirrels sleep from daily to yearly time scales. Finally, we investigate the rhythmicity of red

102 squirrel sleep and whether or not perturbations in ambient food availability affect sleep patterns.

103 Altogether, we use a homeogram along with conventional analyses of sleep to show how 
104 researchers can engage sleep research in free-living animals without new or invasive data

105 collection (i.e., using accelerometer data).

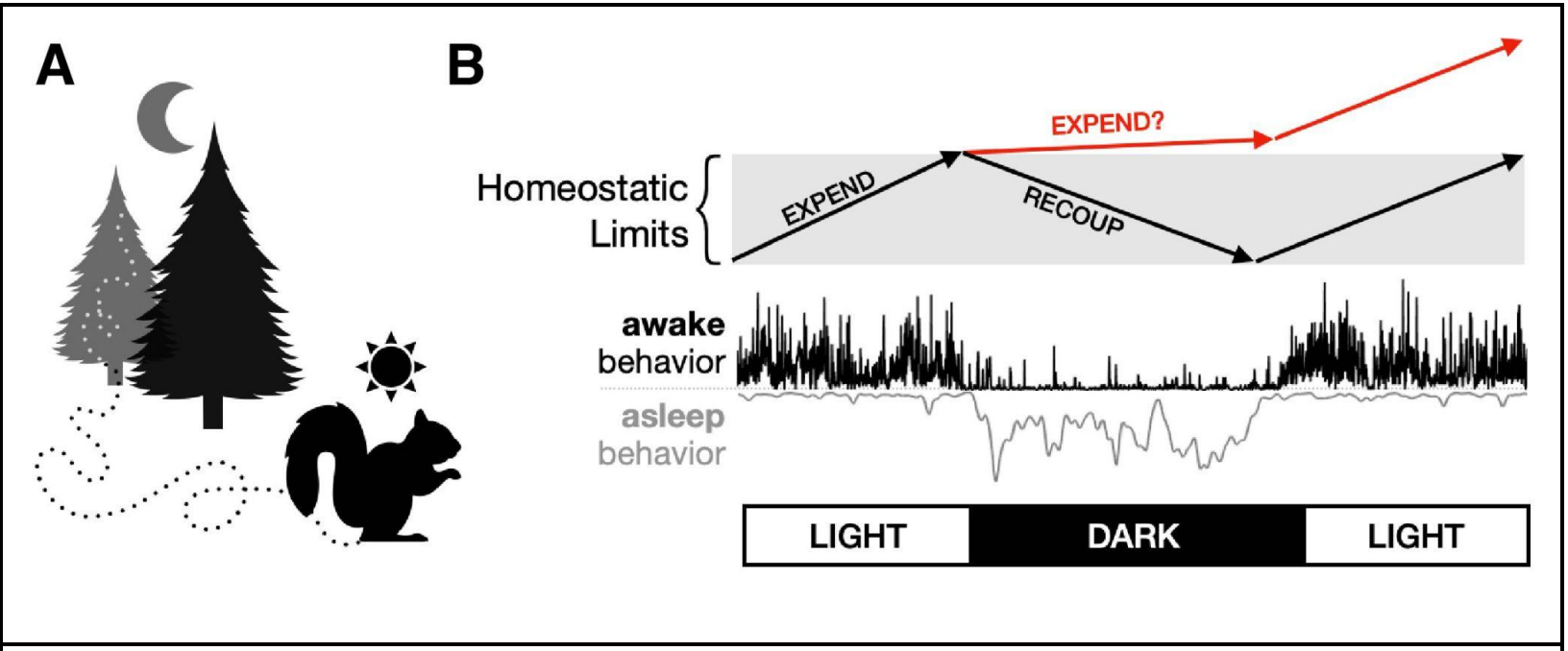

Figure 1. The Missing Link in Accelerometer Data. (A) Accelerometers typically focus on quantifying active behaviors, but not quiescent ones like sleep. (B, top) Because they quantify movement, an accelerometer is inherently 'positive-only' data. From a physiological perspective, this reflects expenditure but not recuperation, and therefore needs to be modified if those data need to be interpreted in a homeostatic model (i.e. where expenditure and recuperation are roughly equalized over a period of time). (B, bottom) These mock data incorporate a conceptualization of homeostatic processes actually occurring in an animal; an ideal method to detect sleep should recognize that sleep is a behavior with amplitude and inertia, rather than simply the absence of movement. 


\section{Application}

\section{Homeogram Construction}

109 The homeogram takes its name from the actigram, which is a time-series histogram indicating

110 activity magnitude as recorded by an accelerometer or other activity sensors (e.g., running wheel

111 encoder, infrared beams, piezoelectric plates). In contrast, a homeogram attempts to use similar

112 data to estimate expenditure (as positive numbers) and recuperation (as negative numbers). Thus,

113 a homeogram is designed to reflect the fact that sleep has both a circadian process and

114 homeostatic value. That is, it is assumed an organism maintains an energetic equilibrium over

115 time (Refinetti, 2007). Under that premise, the basic chain of processing a signal from raw

116 accelerometer data to a mutually exclusive asleep and awake classification is straightforward

117 (Figure 2A). This begins by computing overall acceleration (OA), which is the sum of the

118 absolute value of all accelerometer axes after subtracting a running median to remove static

119 acceleration (Equation 1); for our data, we used a median window of 91 seconds, which was

120 empirically determined based on a sensitivity analysis developed by Shepard (2008) and which

121 we previously applied to red squirrels (Studd et al., 2019). This has similarities to the original

122 development of overall dynamic body acceleration (ODBA, R. P. Wilson et al., 2006) but does

123 not exclude the possibility of low accelerometer sampling rates $(\leq 1 \mathrm{~Hz})$ that do not accurately

124 delineate static versus dynamic movements. In fact, we further downsampled our data by a factor

125 of 60 using a moving mean over the original $1 \mathrm{~Hz}$ data to an effective rate of once-per-minute

$126(0.0167 \mathrm{~Hz})$ to support data exploration and hypothesis testing without the need of an advanced

127 or complex computing workflow. 


$$
O A=\operatorname{abs}(X-\operatorname{medfilt}(X, l))+\operatorname{abs}(Y-\operatorname{medfilt}(Y, l))+\operatorname{abs}(Z-\operatorname{medfilt}(Z, l))
$$

where $X, Y$, and $Z$ are raw accelerometer values and $l$ is the length of a moving media

Equation 1. Pseudo code for determining overall acceleration (OA).

The homeogram uses progressively summed layers of a locally regressed quadratic filter

131 (LOESS) which has superior qualities to a moving mean or Gaussian window because of its local 132 sensitivity to changes in OA amplitude (Figure 2B). The first filter length is the size of day

133 length or night length, whichever is least. Therefore, the 'base' of the homeogram has similar

134 smoothing qualities for long and short days and conceptually represents the ebb and flow of

135 expenditure and recuperation — or sleep-wake activity_of a diurnal or nocturnal animal.

136 Subsequent layers are summed using progressively smaller windows at 1-hour intervals (24

137 filters total) which add detail to the circadian base. Cruder determinations of sleep-wake cycles

138 may choose to use fewer filter layers, whereas polyphasic phenotypes from animals that sleep in

139 many short bouts throughout the day may benefit from eliminating the base layers, and

140 hibernators from adding them (revisited in the Discussion).

141 The final step to create the homeogram is to normalize it, which is useful to ensure all

142 data - which may be coming from different sources - has similar characteristics before the

143 asleep-awake classes are applied. Theoretically, this makes the specific recording properties of

144 the accelerometer hardware (or activity sensor) unimportant. We accomplished this by first

145 estimating where quiescence exists after the filtering and layering stage by applying a Z-score

146 transformation (Figure 2C, D). The mean and standard deviation of segments with a Z-score less

147 than zero were used again on the original signal to create the homeogram. Note that this process

148 results in a time-series where the mean is not zero, and therefore, the homeogram is not a Z-score 
as it is conventionally defined. Conceptually, this approach treats quiescent data segments as periods that estimate accelerometer 'noise' and which should be relatively consistent across all

151 data. Although, we acknowledge that interventions that could enhance animal movement during

152 these times (e.g., disturbances, increasing rapid eye movement sleep) might need more careful

153 handling if they are important characteristics of the final analysis. Once the homeogram is

154 created, it can be used as a time-varying probability that the animal is asleep (where negative

155 numbers indicate a higher probability), or binarized about zero where positive values are awake,

156 and values less than or equal to zero are asleep. The binary form can be easily used to identify

157 sleep transitions (awake $\rightarrow$ asleep $\rightarrow$ awake), where the gradient of the signal is non-zero.

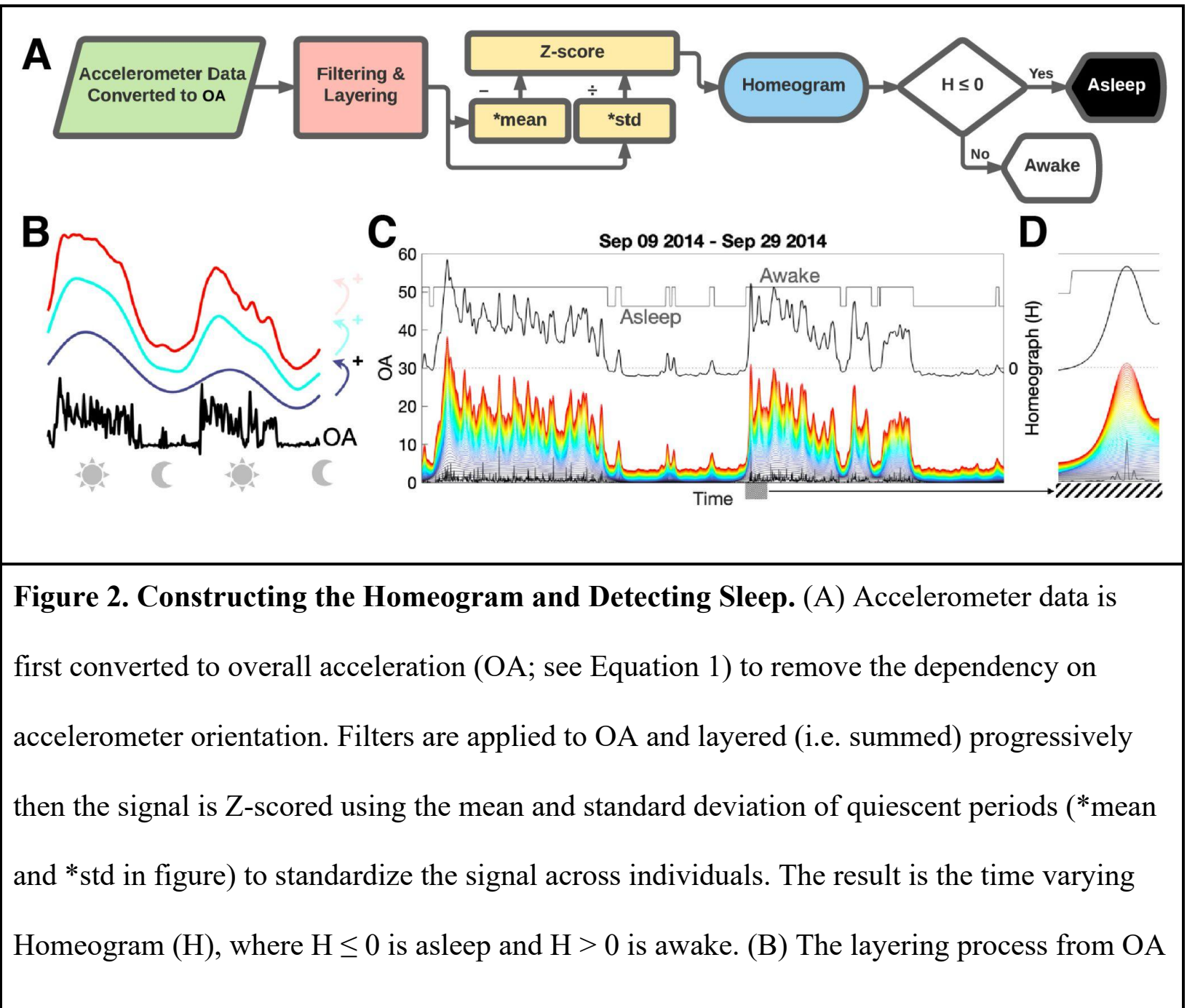


of a diurnal animal (black, bottom) showing the progressive filters that are layered on top of each other; blue is the first filter layer, cyan is the sum of the first and second, and so on until all layers are summed (depicted in red). (C) Actual resolution of filtering and layering from a free-living squirrel collected September 9-24, 2014. The top-most line (red) is what enters the Z-score process, resulting in the Homeogram (black line, right y-axis). The binary asleepawake classification is shown atop. (D) A zoomed-in view of $\mathrm{C}$ for the hatched area.

\section{Homeogram Validation: Nest Attendance}

159 External temperature sensors affixed to an animal (such as on a collar or harness) can be a useful

160 surrogate for determining if an animal is inside of a nest or burrow given that the temperature

161 should rise for endothermic animals (Studd et al., 2016) and act as a gatekeeper for classifying

162 active, waking behavior (Studd et al., 2019). While it might seem like a useful feature to also 163 gate sleep classification, some animals — such as red squirrels - are often observed outside of

164 their nest sleeping or basking in the sun, rendering the collar temperature data a problematic

165 determinant of sleep itself, nonetheless, a good estimate of overall nest use patterns (Steele \&

166 Koprowski, 2003). Collar temperature also approximates qualities of thermal-based validation

167 measured previously used to assist in delineating sleep from wake (Loftus et al., 2021). As a first

168 step in understanding if a homeogram concurs with these expectations, we quantified the

169 relationship between nest attendance and asleep behavior from a multi-year dataset of red

170 squirrels (see Figure 3) by extracting the binary determination of each, where nest attendance

171 was based on collar temperature and asleep-awake state based on our homeogram approach

172 using accelerometry. 
We found the expected pattern of nest-asleep behavior (Figure 3A). Most notably,

174 Winters are characterized by an increased amount of time in the nest — both awake and asleep-

175 whereas animals transition to being more outside-and-awake towards Autumn (Studd et al.,

176 2020). The presence of some sleep outside of the nest is consistent with the observation that

177 sleep may not always occur in the nest. Furthermore, nest attendance does not directly equate to

178 sleep but is highly correlated (Figure 3B). Plotting the residuals from this relationship shows a

179 left-shift for Autumn (Figure 3C), suggesting a more efficient use of the nest for sleep (i.e.,

180 squirrels sleep a higher proportion of time when in the nest). Summer exhibits a mirrored pattern,

181 suggesting less efficient use of the nest for sleep, whereas Winter and Spring are neutral in this

182 regard (i.e. normally distributed).

183 To further investigate these features and control for repeated observations of the same

184 squirrel, we used a linear mixed effects model that included sex and season as fixed effects and

185 squirrel identity as a random effect (Table S2-4). Squirrels spent significantly more total time

186 sleeping (in nest and out of nest) in the Winter and Spring months compared to Summer and

187 Autumn (Tukey's $\mathrm{p}<0.0001$ for all pairwise comparisons), whereas there was no difference in

188 total time spent sleeping between Summer and Autumn (Tukey's $p=0.57)$. Overall, there was no

189 significant effect of sex on total time sleeping $(p=0.136)$ or sleep outside of the nest $(p=0.151)$

190 but females slept less in the nest $(\mathrm{p}=0.0259)$.

191 In summary, the homeogram meets our expectations both visually and analytically as a

192 method to extract asleep-awake behavior using accelerometry. Even movements in the limited

193 volume of a nest are reliably identified as wakefulness which is an important distinction from

194 analyses that treat nest attendance as sleep or rely on 'first nest exit' and 'last nest entry' as a

195 proxy for sleep patterns (see Wassmer \& Refinetti, 2016, Fig. 7). While we benefited from prior 
196 work that established an algorithmic nest classification from collar temperature (in essence,

197 labeling our data), future implementations of the homeogram do not rely on these multisensor

198 data, but may benefit from them. Furthermore, when we tested the homeogram against a widely

199 used accelerometer algorithm (Sadeh et al., 1994) on human data, we found 95.54\% agreement

200 (Figure S2), confirming that it is generally accurate, but benefits from the features described

201 here.
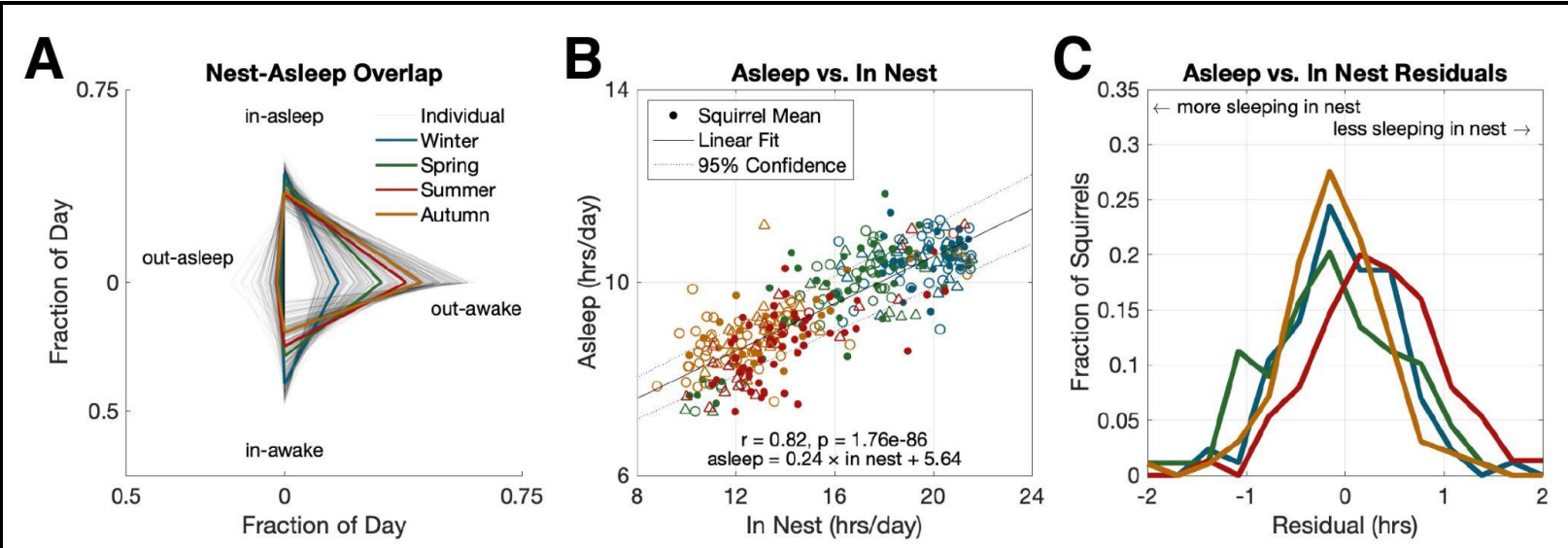

Figure 3. Sleep-wake states and nest attendance. (A) Fraction of day (i.e., time) spent between sleep and nest states (345 recording sessions representing 218 squirrels) over four seasons (mean values in colored lines which apply to all subplots). In-nest and out-nest were determined using collar temperature data (Studd et al., 2019). Season was determined by the mean recording day (see breakdown below, Table 1). (B) The relationship between time spent Asleep (determined using Homeogram, originating from OA) and In Nest (determined by collar temperature). Squirrels with 1 recording session are solid dot markers $(\bullet), 2$ recording sessions are open triangle markers $(\Delta)$, and 3 or more recording sessions are open circles $(\circ)$ colored by season. Pearson linear correlation values are shown along with the best-fit line equation. (C) Residuals from B for each season highlighting seasonal differences in times 
bioRxiv preprint doi: https://doi.org/10.1101/2021.10.14.464397; this version posted October 16, 2021. The copyright holder for this preprint (which was not certified by peer review) is the author/funder. All rights reserved. No reuse allowed without permission.

spent in nest sleeping. 
204 Once sleep is binarized using the homeogram, compiling a set of sleep statistics is trivial (Table

205 1). Briefly, we split our data from red squirrels into four equally sized seasons based on mean

206 day length (i.e., time between sunrise and sunset) between Spring and Autumn; this resulted in

207 two seasons where behavior could be directly compared since light availability is nearly equal.

208 Sunrise, sunset, and solar noon were derived using a sunrise equation (US Department of

209 Commerce, 2021) that uses the latitude and longitude of our study location of red squirrels in

210 Yukon, Canada (60 $\left.45^{\prime} 16.0344^{\prime \prime},-137^{\circ} 30^{\prime} 42.4074^{\prime \prime}\right)$ and daylight savings time (DST) was

211 corrected by applying the local time zone in MATLAB. Note, universal standard time (UTC) is

212 advised when DST might not be coordinated between sensors and observers since it is not

213 affected by DST.

214

215 Table 1. Sleep statistics for North American red squirrels in Yukon, Canada derived from

216 homeogram using accelerometry data. Sleep transitions characterize awake to asleep or vice

217 versa.

$\begin{array}{cccccc} & \text { Winter } & \text { Spring } & \text { Summer } & \text { Autumn } & \text { All } \\ \text { Day of Year } & 311-35 & 36-127 & 128-218 & 219-309 & 1-366 \\ \text { Recording Sessions } & 84 & 88 & 75 & 98 & 345 \\ \text { Unique Squirrels } & 71 & 67 & 66 & 68 & 218 \\ \text { Day Length (hrs.) } & 6.55 \pm 0.79 & 12.44 \pm 2.52 & 18.21 \pm 0.81 & 12.37 \pm 2.47 & 12.38 \pm 4.52 \\ \text { Sleep per day (hrs.) } & 10.46 \pm 1.90 & 9.91 \pm 2.16 & 8.73 \pm 2.01 & 8.73 \pm 1.70 & 9.51 \pm 2.10 \\ \text { Sleep in daylight (hrs.) } & 0.73 \pm 0.87 & 1.88 \pm 1.67 & 4.29 \pm 2.04 & 0.88 \pm 1.45 & 1.96 \pm 2.14\end{array}$




$\begin{array}{cccccc}\text { Sleep in darkness (hrs.) } & 9.73 \pm 1.82 & 8.03 \pm 1.75 & 4.44 \pm 1.07 & 7.85 \pm 1.24 & 7.55 \pm 2.56 \\ \text { Total sleep transitions } & 28 \pm 7 & 24 \pm 8 & 19 \pm 7 & 14 \pm 6 & 22 \pm 9 \\ \text { Sleep transitions in daylight } & 3 \pm 3 & 6 \pm 4 & 13 \pm 6 & 4 \pm 4 & 7 \pm 6 \\ \text { Sleep transitions in darkness } & 25 \pm 6 & 18 \pm 7 & 6 \pm 4 & 11 \pm 5 & 16 \pm 9\end{array}$

218 We compiled mean asleep values around a 60-day window for each day of the year

219 (Figure 4). This visualization can also be conceptualized as the sleep probability of a red squirrel

220 at any day and time. These results demonstrate the robust plasticity between sleep phenotypes

221 based on season for red squirrels. Winter is highlighted by relatively inconsistent sleep, which

222 accounts for a lower level of sleep in darkness, as well as a small peak during the day where naps

223 (sleep in daylight) — or at least, deep rest — may be taking place. Despite the importance of

224 Spring as it relates to reproduction, it sticks out as a period of a gradual transition to the long

225 Summer days, where pre- and post-noon naps sprout, consistent with our finding that a large

226 amount of sleep occurs during the day in Summer (see Table 1). Autumn is more well-defined

227 and sharply delineated than Spring, likely a result of the stricter demands on daily activity, and

228 perhaps, nightly recovery. 


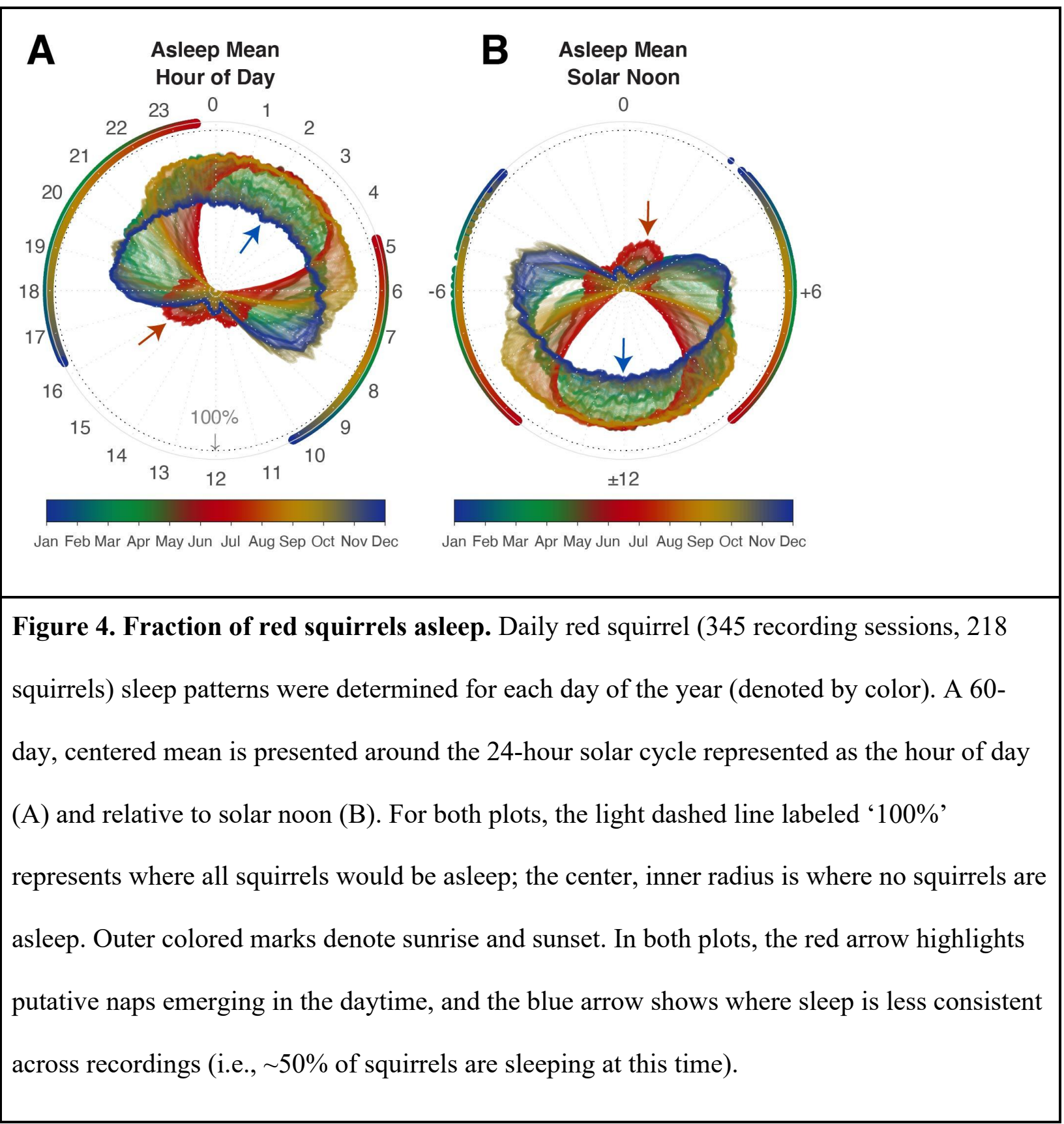

Figure 4 can be easily converted to a time-series plot to understand the nature of sleep

231 phenotypes for each season (Figure 5). These results show how season determines a sleep

232 phenotype, rather than day length, by comparing Spring and Autumn. The strong transitions at

233 sunrise and sunset of Autumn and the small variance in daytime sleep suggest a 'seize the day'

234 approach to this important season where squirrels spend their time caching cones from white 
235 spruce trees (Picea glauca) to serve as a food source for the coming winter (Fletcher et al., 2010;

236 McAdam et al., 2019).

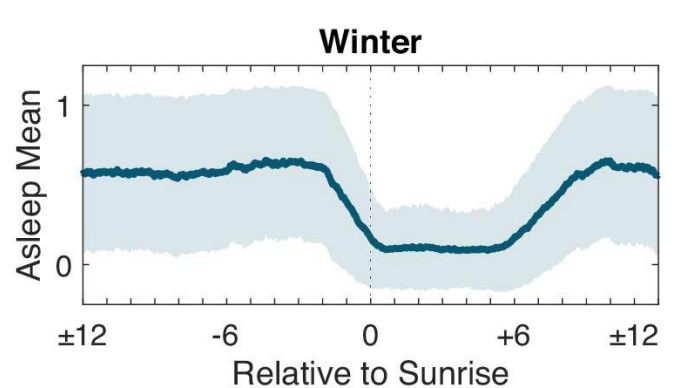

Spring

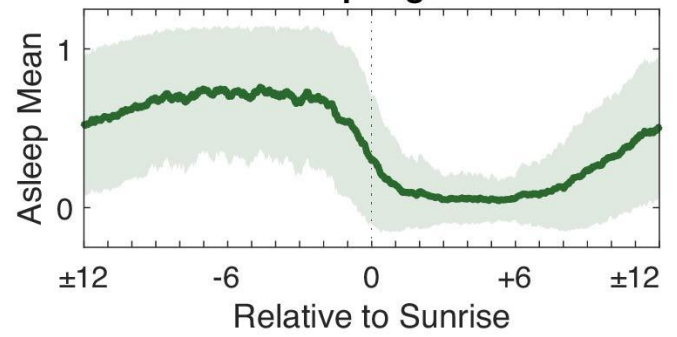

Summer

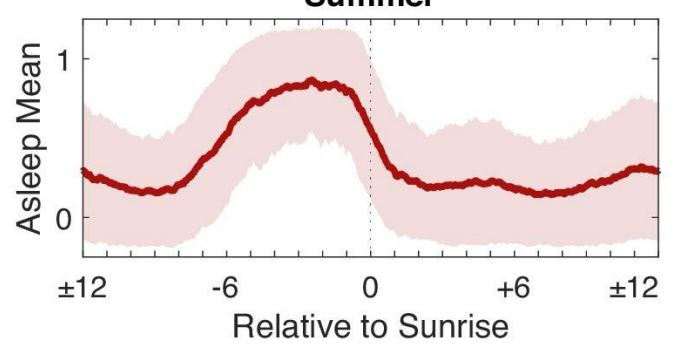

Autumn

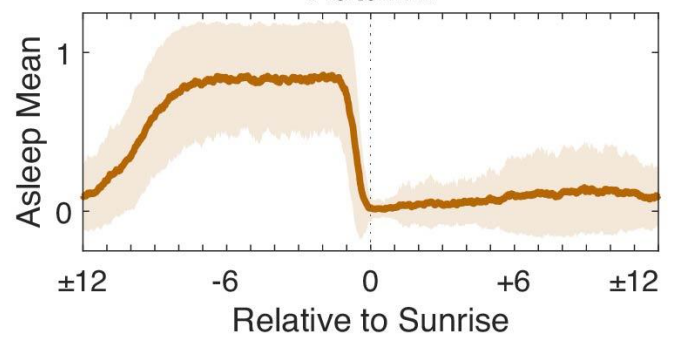

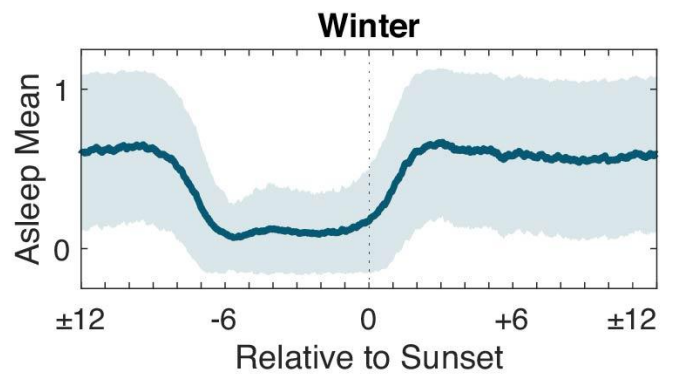

Spring

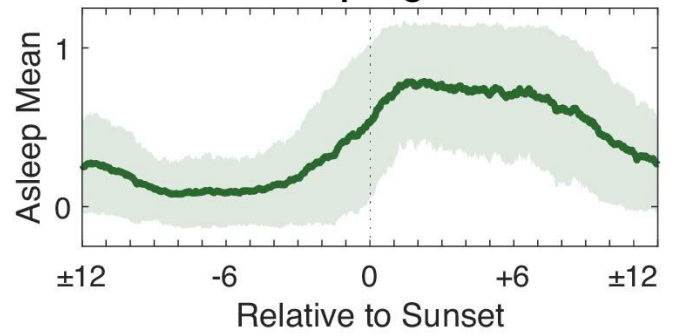

Summer

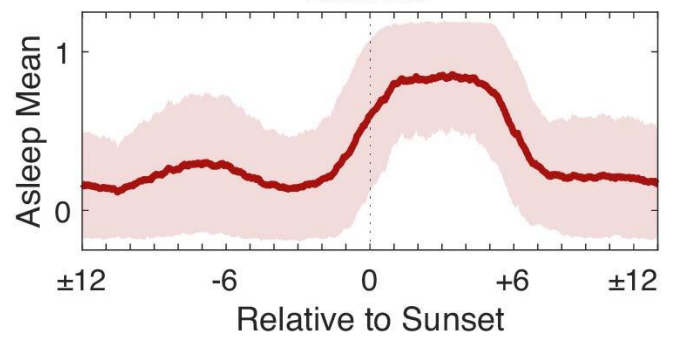

Autumn

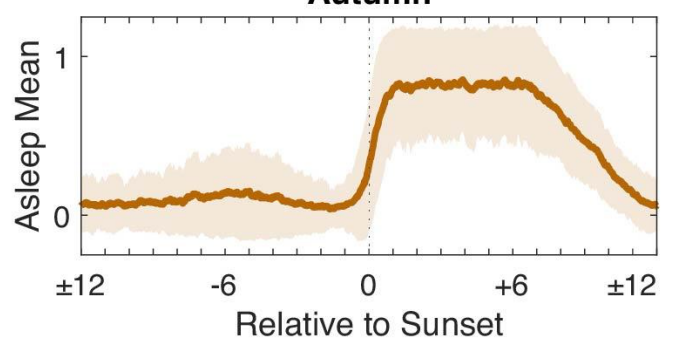

Figure 5. Asleep Mean and Standard Deviation. Binary asleep-awake states were determined from the homeogram (where asleep $=0$, awake $=1$ ) and used to determine the time-varying mean and standard deviation relative to sunrise (left column) and relative to sunset (right column). 


\section{Rhythmicity Analysis}

238 Rhythmicity is a measure of how consistent a behavior (e.g., sleep) pattern is over time.

239 Rhythmicity can be a useful metric to compare across seasonal or interventional conditions since

240 entrainment is a fundamental component of organismal biology and can correlate with overall

241 health and condition (Mistlberger \& Rusak, 2011). In brief, the rhythmicity of a signal can be

242 quantified using an autocorrelation analysis. This method scrubs a signal across itself and

243 calculates a correlation between those lagged signals. Thus, at a lag of 0 , the autocorrelation is

244 always 1 and symmetrically extends to each side for positive and negative lags up to the length

245 of the data. Therefore, rhythmic data will exhibit positive peaks at locations $n$-cycles from a lag

246 of 0 . To showcase its utility, we hypothesized that a rhythmicity analysis would further support

247 Autumn as the bourgeonner of highly regulated sleep-wake behavior in red squirrels, as well as

248 resolve the ultradian rhythms (i.e., naps) embedded in Winter and Summer (see Figure 4).

249 We modified the binary awake-asleep classification from the homeogram approach

250 described above such that sleep was negatively signed (-1) and awake was positively signed (+1)

251 so they would have the properties of a standard unit oscillation. Each recording session was then

252 autocorrelated and averaged for each season (Figure 6, left). As we expected, primary rhythms

253 were present at 24-hour intervals across all seasons. We calculated the rhythmicity index (RI) as

254 the third peak (including the 0-lag condition) (Dowse, 2009; Levine et al., 2002) which revealed

255 Autumn as the most rhythmic season for awake-sleep patterns. The adjacent season of Winter

256 has an RI of nearly half, altogether consistent with our prior results suggesting that sleep is most

257 variable in Winter.

258 We then aimed to quantify potential ultradian (i.e., less than 24-hour) peaks by focusing

259 on the autocorrelation centered about 12-hours (Figure 6, right). A purely monophasic circadian 
260 signal with sleep opposed to wakefulness would exhibit a strong negative correlation at 12-hours

261 lag, whereas, if harmonics (i.e., ultradian rhythms) existed, the negative peak would be

262 interrupted with positive correlations. We found ultradian peaks that were invariably unimodal,

263 so we identified the single largest peak and quantified its magnitude over the local minima.

264 Spring and Autumn exhibited minuscule ultradian rhythms, whereas Winter and Summer were

265 the largest. For comparison, Winter's ultradian rhythm amplitude was 22.3 times larger than

266 Spring's, 6.0 times stronger than Autumn's, and 1.5 times stronger than Summer's. The Winter

267 and Summer rhythms were only slightly phase-shifted from the primary rhythm. Based on our

268 previous data showing the potential for napping in Winter and Summer, we interpret this result

269 as suggesting that when naps do occur, they are nearly perfectly out of phase with the primary

270 sleep rhythm. For instance, red squirrels are most likely to be asleep around 3-4 A.M. and most

271 likely to nap $-180^{\circ}$ out of phase — around 3-4 P.M. 

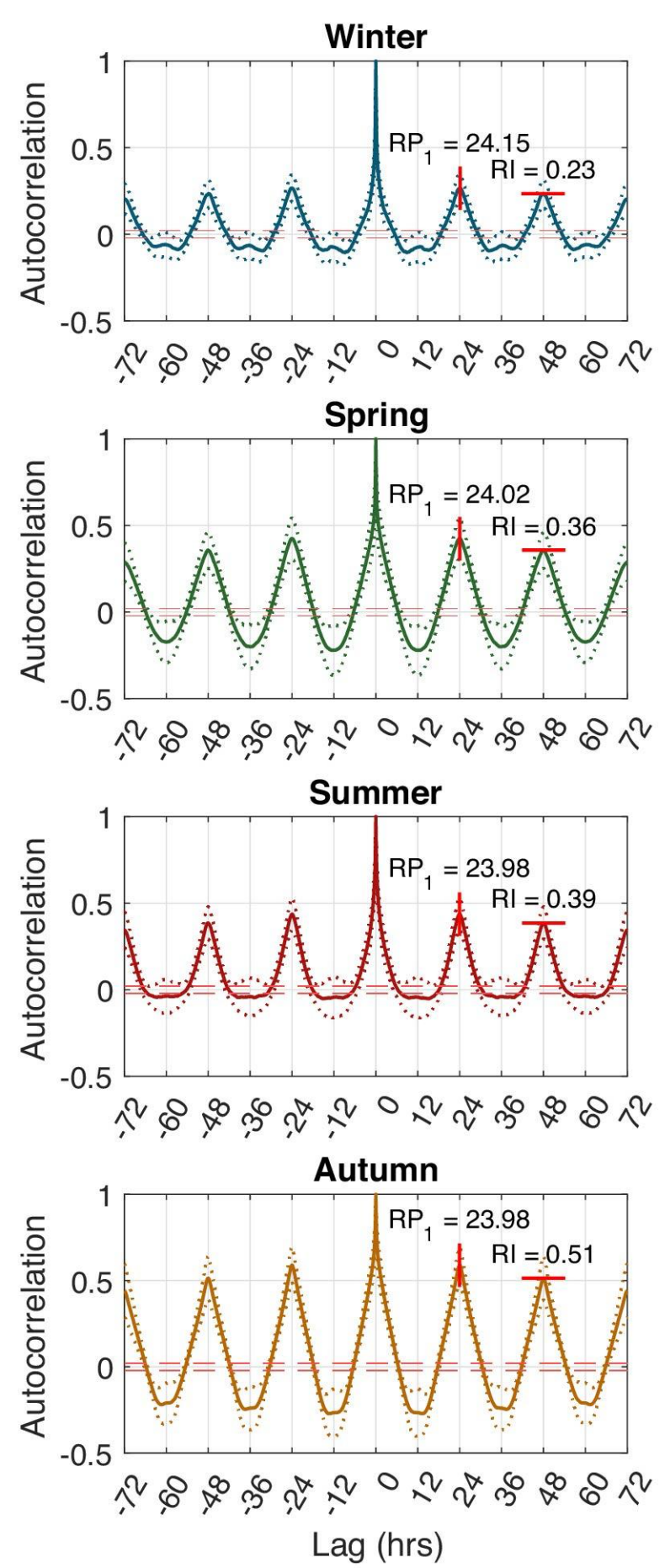
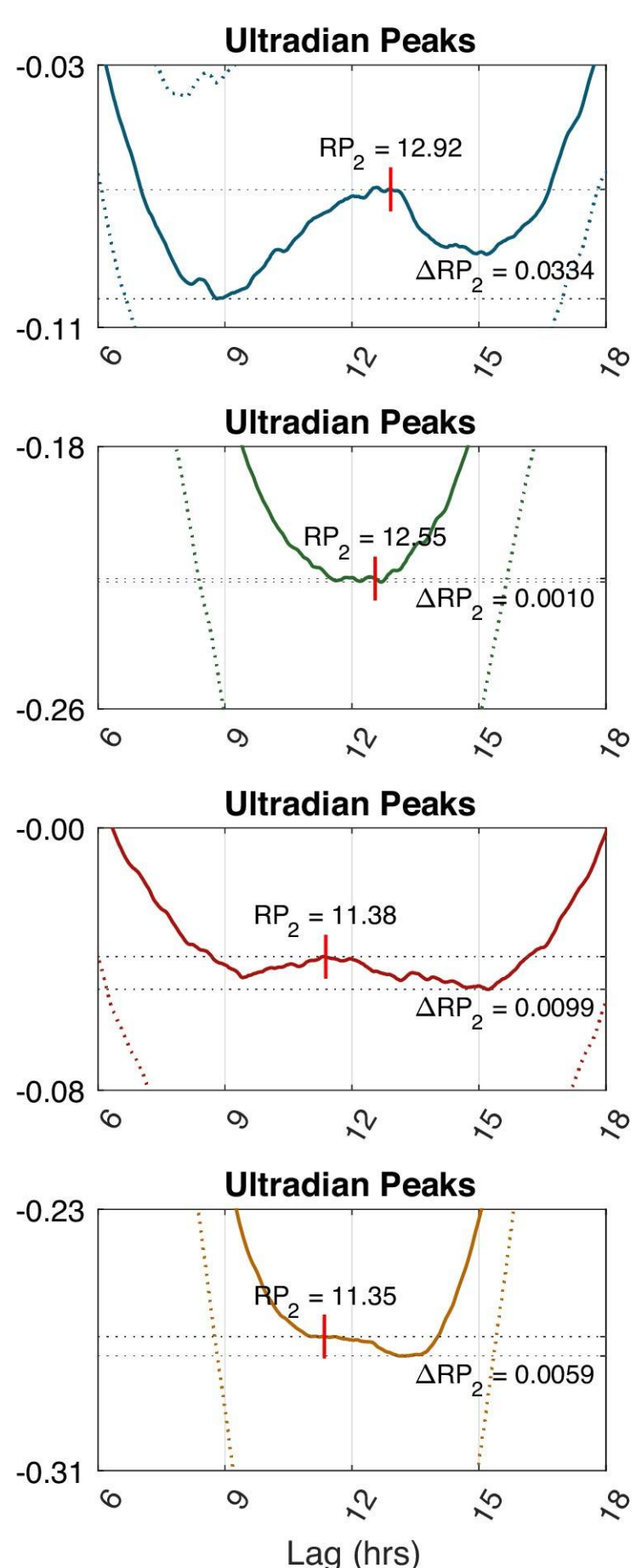

Lag (hrs)

Figure 6. Sleep Rhythmicity. The autocorrelation of sleep quantifies the period and intensity of its underlying rhythm. (Left column) The primary rhythm period $\left(\mathrm{RP}_{1}\right)$ is the circadian 
rhythm (i.e., roughly 24-hours). The Rhythmicity Index (RI) quantifies the rhythm intensity as the third peak. Values between the red dashed lines (95\% confidence) are considered ambiguous. (Right column) The secondary rhythm period $\left(\mathrm{RP}_{2}\right)$ is the ultradian rhythm. $\Delta \mathrm{RP}_{2}$ is the greatest local change in rhythm intensity. For both plots, standard deviations are dashed lines.

273 A rhythmicity analysis based on the homeogram may be useful in discerning subtle sleep

274 dynamics across fluctuating environmental conditions. For example, under non-stressful

275 situations the hypothalamic-pituitary-adrenal axis operates under circadian control, however,

276 exposure to external stressors may result in central nervous system activation that disrupts a

277 healthy sleep schedule (Vargas et al., 2018). We were able to test this by investigating the

278 change in RI during years in which white spruce trees produced a superabundance of cones

279 available to squirrels in late Summer and early Autumn, which are known as mast years (Kelly,

280 1994). At our study site in Yukon, red squirrels primarily consume the seeds contained in white

281 spruce cones, which they collect and cache underground in the Autumn of each year (Fletcher et

282 al., 2010, 2013). Mast years occur every 4-6 years during which squirrels exhibit an extended

283 breeding season, increased reproductive output, and substantial increases in cone hoarding

284 behavior (Boutin et al., 2006; Dantzer et al., 2020; McAdam et al., 2019). Our hypothesis was

285 that this naturally occurring condition would preferentially increase RI for Autumn of mast

286 years, when red squirrels are busy hoarding and caching cones, since a stricter sleep presumably

287 reduces the transition cost (i.e., latency to and from waking behavior) and increases overall

288 productivity. 
We compiled the RI for all recording sessions and examined its relationship to non-mast

$290(2015,2016,2017)$ and mast $(2014,2019)$ years, and season (Figure 7). Consistent with the

291 autocorrelation data, Autumn accounted for the largest RIs, which also appeared to be associated

292 with a mast year. When we compared the distribution of RIs for each season, we found that the

293 only significant difference was between Autumn non-mast and mast years $\left(p=2.95^{-14}\right.$, one-way

294 ANOVA), supporting our hypothesis that the increased demands of a spruce mast year enhance

295 the rhythmicity of sleep-wake patterns.

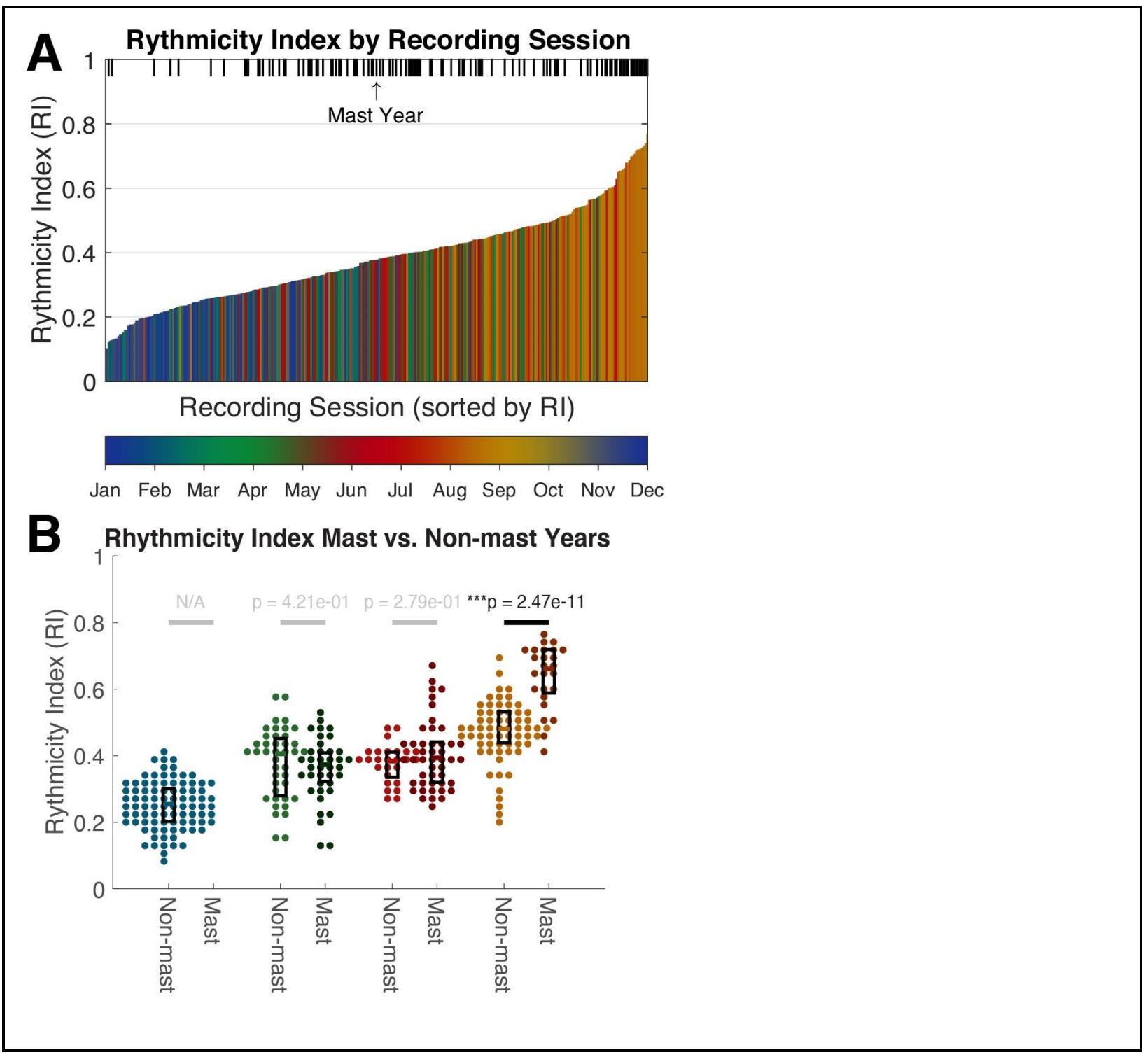


Figure 7. Rhythmicity Index by Recording Session and Season. (A) Recording sessions from each season are color coded and sorted by rhythmicity index (RI, y-axis). Mast years, where food is super-abundant and physical demands are increased due to hoarding and caching are marked with a vertical pipe along the top. (B) Beeswarm plot of RI for each recording session $(\bullet)$ colored by season (from left to right: Winter, Spring, Summer Autumn) and organized by Mast and Non-mast years. P-values of the one-way ANOVA testing the null hypothesis that the means of the groups are equal is shown above each Mast vs. Non-mast season group. We did not have Winter mast data.

297 It has been debated whether or not observed behavioral rhythms are the result of a 'masking 298 effect' whereby discrete events, like sunrise and sunset, gate behavior rather than behavior being 299 regulated endogenously (Rietveld et al., 1993). We hypothesized that sleep patterns were masked 300 by sunrise and sunset, since daylight has a strong influence on the ability of a diurnal animal to 301 forage and navigate, as well as visually identify threats. We used homeogram data to compile 302 transition times in a 60-day window for each day of the year (similar to Figure 4) and plotted 303 them aligned to sunrise and sunset or centered about solar noon (Figure 8). Both transition types 304 have a subtle gradient across seasons. For example, as Autumn progresses, transitions to awake 305 precede sunrise and follow sunset to a greater degree. When aligned to solar noon, the gradation 306 largely disappears, not supporting our hypothesis concerning masking. Rather, this analysis 307 suggests that the circadian clock is entrained to solar noon, when the sun passes the local 308 celestial meridian and exerts the greatest amount of solar energy on earth. In other words, each 309 sleep season appears to be determined by a solar-centered sleep quota rather than sunrise and 
310 sunset. Autumn and Spring can be compared as equivalents and exhibit large differences in sleep

311 transitions, which supports our previous findings that sleep-wake behavior is plastic and may be

312 based on behavioral demands or is indeed shaped through the feedback of those behaviors on the

313 squirrel's physiology.

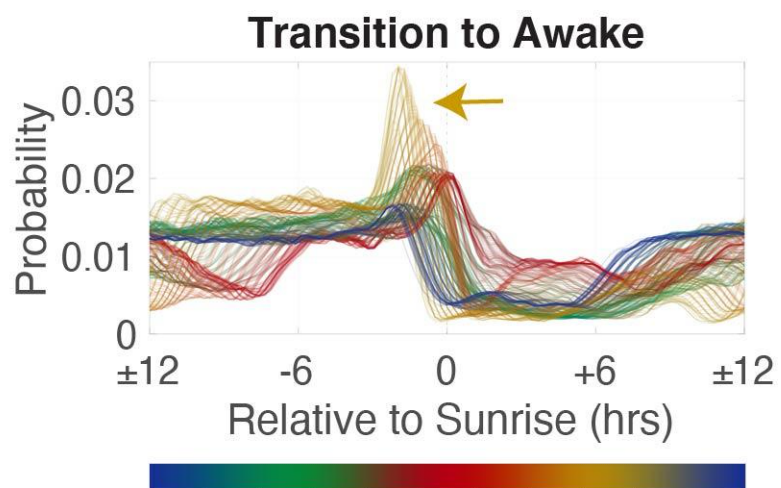

Jan Feb Mar Apr May Jun Jul Aug Sep Oct Nov Dec
Transition to Asleep

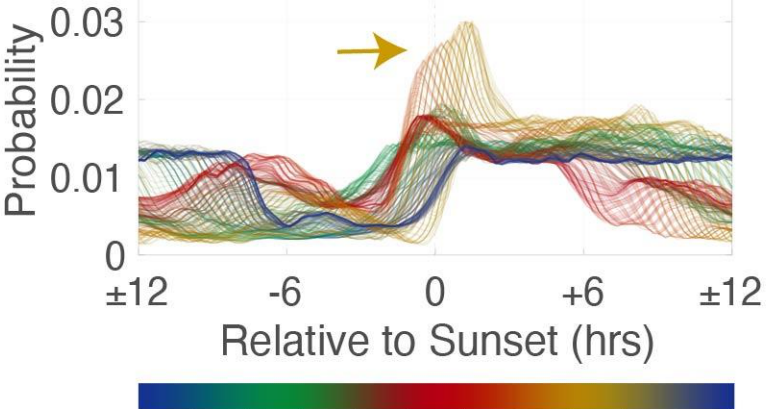

Jan Feb Mar Apr May Jun Jul Aug Sep Oct Nov Dec

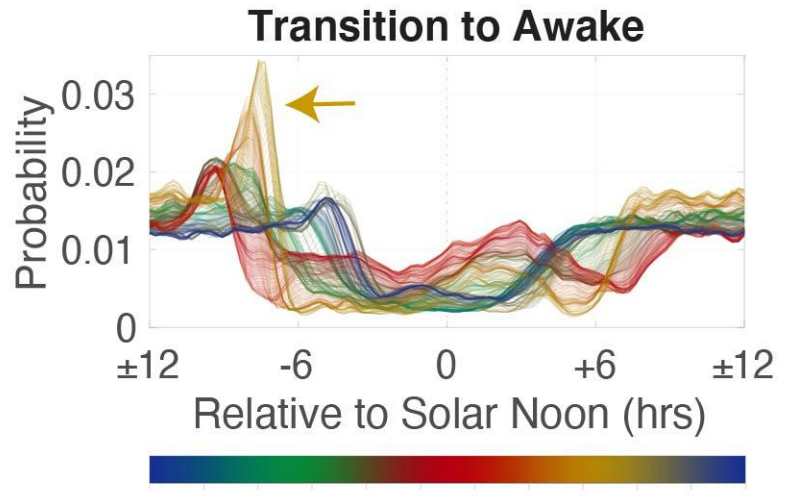

Jan Feb Mar Apr May Jun Jul Aug Sep Oct Nov Dec
Transition to Asleep

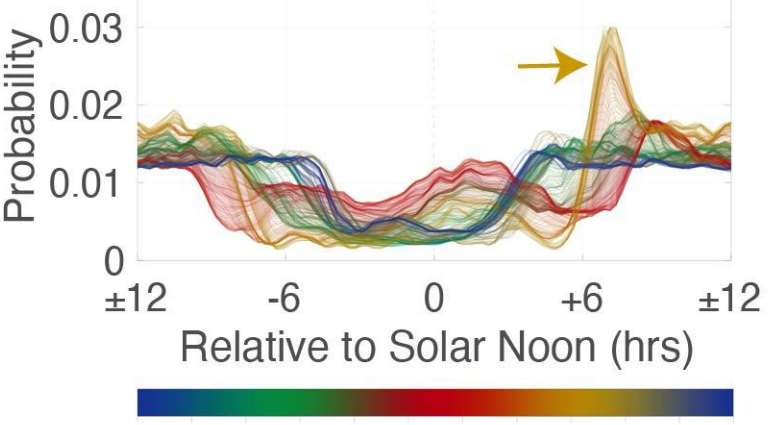

Jan Feb Mar Apr May Jun Jul Aug Sep Oct Nov Dec

Figure 8. Sleep Transitions. Sleep transitions were calculated from the binary form of the homeogram and the probability for 60-day windows around a single day of year are plotted for transitions to the awake state (left column) and transitions to asleep (right column). The top row is transition probability relative to sunrise and the bottom row is transition probability 
relative to solar noon. The same sleep transitions (marked by arrows) are graded when relative to sunrise (top row) but become aligned relative to solar noon (bottom), namely in days of the Autumn season.

317 sleep bout analyses. That is, how often sleep is interrupted and the duration of each sleep bout, 318 respectively. We hypothesized that sleep becomes less fragmented or 'deeper' in red squirrels in 319 response to great physical/behavioral demands required to harvest and hoard spruce cones in the 320 Autumn (Studd et al., 2020; see also Fletcher et al., 2010). We defined sleep duration as the 321 period between a transition to asleep and transition to awake and confirmed that they can be 322 described by a power law (Dimanico et al., 2021; Lo et al., 2002, 2004). Evidently, sleep 323 duration distributions are significantly different between each season $(\mathrm{p}<0.0001$ for each 324 pairwise comparison using Two-sample Kolmogorov-Smirnov test), where Winter sleep 325 durations are shorter and Autumn sleep durations are longer (Figure 9). We next examined our 326 data separated into mast $(2014,2019)$ and non-mast $(2015,2016,2017)$ years to test if squirrels 327 exhibited longer sleep durations in an environment of increased physical demands associated 328 with caching cones (Boutin et al., 2006; Dantzer et al., 2020; Fletcher et al., 2010; McAdam et 329 al., 2019; Studd et al., 2019). Despite not having mast year data for Winter, we found that 330 Summer $(\mathrm{p}=0.0288)$ and Autumn $\left(\mathrm{p}=1.28^{-20}\right)$ had significantly longer sleep durations in mast 331 years than non-mast years. Furthermore, Summer mast sleep durations were less than Autumn 332 non-mast sleep durations, and Autumn mast sleep durations were longer than all others (Figure 9 333 inset). 
Overall, sleep transitions are reduced in Autumn, which could simply be due to the

335

336

337

338

339 demands.

increase in daily activity caused by caching cones. This is supported by the observation that sleep duration in darkness (but not daylight) is similar between Spring and Autumn (mast and nonmast; see Table 1). However, because of the Spring and Autumn day length equivalence, we could compare sleep transitions in the dark, which are far fewer in Autumn (Table 1). Most interesting is that the overall duration of sleep in Autumn is less in a mast year than in Autumn in non-mast years (Table S1). We again used a linear mixed-effects model to investigate the proportion of time spent sleeping in the nest (Table S5-6), which was not affected by sex ( $\mathrm{p}=$ 0.1532). The lack of a significant interaction between mast year and season indicates that no matter mast status, the proportion of time spent sleeping in the nest in Autumn is significantly greater than all other seasons $(\mathrm{p}<0.05)$ except Summer, where it is non-significant in non-mast years $(p=0.0755)$ but significant in mast years $(p<0.0001)$, likely because masting begins at the end of Summer as we defined it here.

In sum, the homeogram developed here allowed us to use accelerometer data to determine sleep rhythmicity, the prevalence of sleep transitions, and the duration of sleep periods. When applied to our data collected from red squirrels in Yukon, a unique model was formed by which squirrels sleep least in Autumn and even less in the Autumn of a mast year, but that sleep is more rhythmic and sounder (i.e., less fragmented and longer bouts), as well as more efficient from a nest-use perspective. Thus, we find support for the hypothesis that squirrels exhibit deeper (i.e., less fragmented) sleep in response to increased ecological and behavioral demands. 


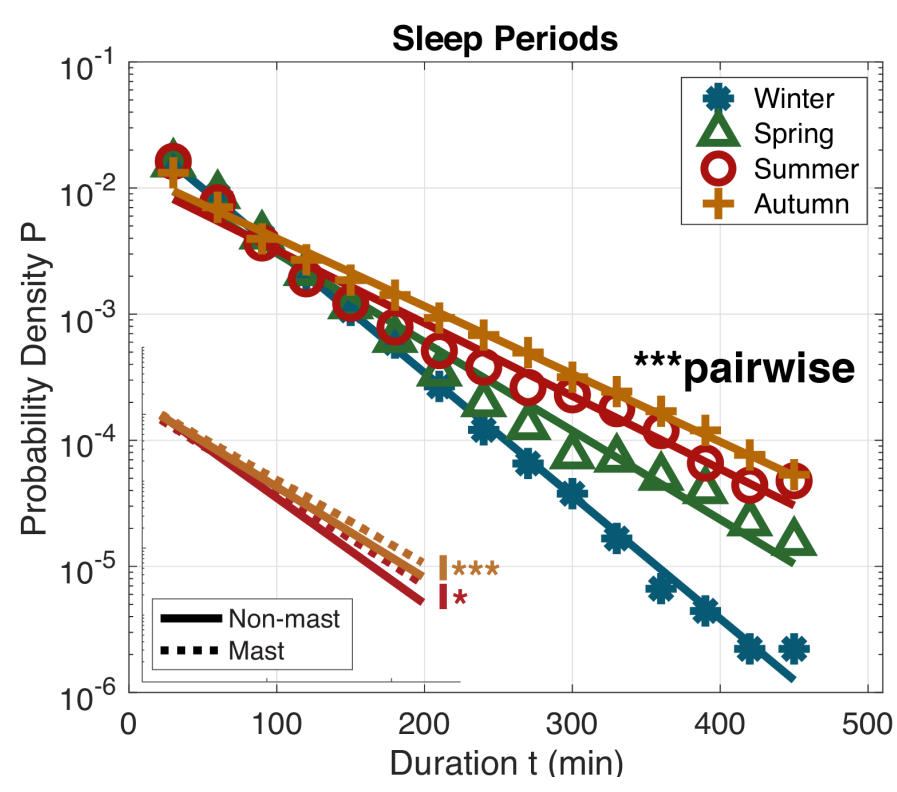

Figure 9. Seasonal Sleep Periods. Semilogarithmic plot for distributions of sleep durations.

Raw binned ( $\mathrm{n}=20$ bins) data are shown with markers with accompanying lines of best fit. All pairwise comparisons were significantly different. Inset shows Summer and Autumn Non-mast (solid) and Mast (dashed) best fit lines with the same axes as the main figure. Mast to non-mast comparisons were non-significant for Spring and mast data was unavailable for Winter. ${ }^{*} \mathrm{p}<$ $0.05, * * * \mathrm{p}<0.001$ Two-sample Kolmogorov-Smirnov test. 


\section{Discussion}

358

359

360

361

362

363

364

365

366

367

368

369

370

371 duration, continuity, and regularity (M. P. Walker, 2017). Below, we expand some of the major

372 themes of our findings and methodological issues moving forward.

\section{Sleep and Homeostasis}

374 Cannon defined the word homeostasis as "the tendency towards stability" in 1939, and nearly

375 five decades later, Borbély integrated a homeostatic rhythm—interacting with a circadian

376 rhythm - into his two-process model of sleep regulation (Achermann \& Borbély, 2011; Deboer,

377 2018). In harmony, these two processes describe the coordination of endogenous and exogenous

378 factors that should enhance the performance and fitness of individuals (Roth et al., 2010). 
The hierarchy of mechanisms engendering homeostasis through sleep depends on its duration and intensity (Tobler, 2011) which can be defined multiple ways. From a behavioral

381 perspective - the one that an accelerometer can see-sleep duration is time spent in the quiescent

382 state, whereas intensity is the extent to which sleep is fragmented. Of course, hidden from the

383 accelerometer are the neural electrophysiological states that are more nuanced. Firstly, sleep

384 onset (and latency to this state after stillness) is typically demarcated by the first occurrence of

385 slow-wave activity (SWA) indicative of non-rapid eye movement (NREM) sleep (Cano et al.,

386 2008; Mckenna et al., 2008). This discrepancy often leads to accelerometers over-estimating

387 sleep duration compared to electrophysiological measures (Ancoli-Israel et al., 2003). Therefore,

388 the behaviorist might rely on a measure of sleep efficiency instead, derived by comparing the

389 time spent still to the time spent in a nest, bed, or resting posture (Lutz et al., 2018). Secondly,

390 the REM state offers the opposite problem in some mammals, especially infants, where the

391 replay of active behaviors (which is normally gated from muscles) is temporarily allowed to pass

392 through the spinal cord, resulting in high amplitude movements like twitching, trembling, and

393 fluttering of the body and limbs (Louie \& Wilson, 2001). We investigated the possibility of

394 identifying such behavior by reconstructing the 3D trajectory of brief movements that were

395 identified as wakefulness, but without a library of video observations or coordinated biopotential

396 recordings, the task complicates rather than simplifies the interpretation of large-scale data. No

397 more than $10 \%$ of brief awakenings in our data were deemed REM candidates. Taken together,

398 there are certainly Type I and Type II errors present (Dekking, 2005), which may

399 counterbalance, but remain a species-specific confound to accelerometry alone. Winnebeck et al.

400 (2018) implemented a novel method of quantifying locomotor inactivity during sleep by

401 amplifying the accelerometer data during putative sleep, which may broadly apply to 
402 distinguishing sleep-wake states. We also generally recognize the possibility that a larger

403 proportion of the day nesting (e.g., Winter) increases the sleep false positive rate due to the

404 limited range of motion that an animal has in a nest.

405 We used sleep fragmentation as a proxy for sleep intensity, which is

406 electrophysiologically indicated by the presence of SWA (Mongrain \& Dumont, 2007; Tobler,

407 2011). It is not uncommon for healthy individuals to experience fragmented sleep. Typically,

408 brief awakenings are not remembered by humans in the morning because sleep inertia is too

409 strong during those times for it to be registered in memory (Kenna, 2017). Sleep typically

410 fragments for mammals at the completion of a sleep cycle, which is the stereotypical progression

411 from a vigilant state to REM or NREM sleep, or the dreaming and homeostatic (i.e., deep sleep)

412 states, respectively. However, it should be noted that REM sleep carries a potentially significant

413 homeostatic value (Ephron \& Carrington, 1966; Naiman, 2017; Pandey \& Kar, 2018; Siegel,

414 2011). Nonetheless, when sleep cycles — and sleep architecture, in general—are disrupted, as

415 evident by fragmented sleep, homeostasis is compromised (Reid \& Zee, 2011). And despite the

416 disparity between sleep cycle duration across species, being about 10 minutes for a small rodent

417 and 90 minutes for a human (Zepelin \& Rechtschaffen, 1974), fragmentation has similar

418 deleterious effects across species (Toth \& Bhargava, 2013). Fragmented sleep can be the result

419 of a disease state or disorder (Jones et al., 1987; Kimoff, 1996; Mellman et al., 1995; Tafti et al.,

420 1992) and effectively reduces optimal daytime vigilance and neurocognitive function (Bonnet,

421 1987; Stepanski, 2002). Indeed, fragmented sleep, which leads to daytime sleepiness, signals that

422 the function of sleep has been inadequately met and remains functionally separate from sleep

423 deprivation itself (Ramesh et al., 2009). In our red squirrel data, we found that Autumn had the

424 least number of sleep transitions and the longest sleep periods, suggesting less sleep 
425 fragmentation. We found that these characteristics were more pronounced in years in which there

426 was a superabundance of food that squirrels needed to collect and cache (mast years), where

427 sleep duration is decreased (Table S1), reflecting a potentially adaptive mechanism to

428 compensate for increased energy expenditure associated with cone collection and caching

429 (Fletcher et al., 2012). Alternatively, activity itself and caloric intake are potent modulators of

430 circulating hormones and circadian rhythms (Dallman et al., 2004; Dolezal et al., 2017; Laposky

431 et al., 2008; Youngstedt et al., 2019), which may lead to better Autumn sleep. Autumn is also

432 marked by enhanced sleep rhythmicity — which, at least in humans — is a desirable health trait

433 (Gibson et al., 2009; Sulli et al., 2018). In fact, loss of circadian tone is a strong predictor of

434 impending death in some, if not most animals (Pittendrigh \& Minis, 1972; Wax \& Goodrick, 435 1978)

436 Ultradian Sleep Rhythms

437 Any rhythm occurring more than once per day is considered ultradian. This includes cycles of

438 sleep states that normally come and go overnight (i.e., sleep architecture) down to heart rhythms.

439 We were interested in the ultradian sleep rhythms that emerged in patterns characteristic of naps,

440 most notably in Summer and Winter for red squirrels. Unlike most polysomnography,

441 accelerometers have the advantage of recording continuously (but see Debellemaniere et al.,

442 2018; Strangman et al., 2018), revealing quiescent patterns that exist outside the typical circadian

443 sleep window (Cornelis et al., 2019; Miller et al., 2020).

444 The parsimonious answer to why we nap is to fulfill the additional requirements of sleep

445 demand or a sleep quota. This is consistent with our findings in red squirrels in the summer

446 months as they appear to sleep almost as much during the day than at night (similar to ground

447 squirrels J. M. Walker et al., 1977). We suspect that the strong gating effect of sunrise and sunset 
448 (Wassmer \& Refinetti, 2016) compresses sleep duration in Summer such that a nap must emerge,

449 just as a tire tube might bulge at its weakest point under immense pressure; therefore, when we

450 nap might be the more interesting question. Despite Summer naps appearing in the afternoon in

451 red squirrels, our rhythmicity analysis suggests that the predominant nap forms a circasemidian

452 rhythm occurring roughly $180^{\circ}$ out of phase ( $\sim 12$ hours) relative to the major, or core sleep

453 period (Broughton, 1998). The reason for this may have to do with the fact that SWA, or

454 homeostatic sleep, is correlated with the previous time spent awake. Thus, it may be

455 advantageous to partition sleep bouts perfectly out of phase to minimize the accumulation of

456 homeostatic pressure. This strategy can be extended to polyphasic sleepers that capitalize on

457 frequent sleep sessions to engage SWA on a nearly continuous basis. One theory posits that

458 every time an organism falls asleep, some process related to recuperation might be activated,

459 allowing sleep benefits to accrue independently of sleep duration (S. Wilson, 1995). It is also

460 known that, for monophasic diurnal animals, the most SWA occurs in major sleep with minimum

461 body temperature, but for minor sleep, it is with maximum body temperature, which is very

462 likely to follow solar noon (S. Wilson, 1995). Therefore, major and minor sleep sessions may be

463 spaced to ideally reduce homeostatic pressure in coordination with ambient and internal body

464 temperatures (Lavie, 1986).

465 The other reason why we nap is to conserve energy and could account for red squirrel

466 naps in the Winter. While increased sleep variability across individuals in Winter likely dilutes

467 the effect in the aggregate, our rhythmicity analysis suggests Winter ultradian rhythms are the

468 strongest of all seasons. Because North American red squirrels do not hibernate or engage in

469 torpor (Brigham \& Geiser, 2012), they have high thermoregulatory demands throughout the year,

470 which may be met by increasing time spent in the nest (by staying warm) while benefiting from 
471 the reduced energetic demands bestowed by sleep (Cerri \& Amici, 2021; Schmidt, 2014). The

472 relatively active morning and evening schedules during Winter likely serve a mixture of

473 nutritional and territorial demands for the red squirrel. This interpretation is not mutually

474 exclusive with the possibility that biological cascades increase sleep demand in the Winter. For

475 example, exposure to acute stressors can promote NREM sleep and also trigger non-shivering

476 thermogenesis (Harding et al., 2020) which may have net positive effects for an animal in

477 extremely cold conditions, especially if nutritional resources are scarce. The frequency of sleep

478 transitions in red squirrels is also highest in Winter. While this may be explained by a higher

479 false-positive rate of sleep detection when an animal spends more time confined to a nest,

480 frequent awakenings may also safeguard red squirrels from entering REM sleep — which occurs

481 at the tail end of mammalian sleep cycles - where the control of body temperature is

482 poikilothermic (i.e. minimal) (Carskadon \& Dement, 2011).

484 We implemented a motion-based sleep state classification that was tuned to identify sleep, but

485 likely made Type I and Type II errors, which is potentially unsolvable using accelerometer data

486 alone. In general, there is a tendency to overpredict the sleep state and underpredict the waking

487 state (Sazonov et al., 2004). The lack of video or electrophysiology makes it impossible to

488 delineate quiet rest from sleep or sleep movements from wakefulness in our data. In laboratory

489 nests, red squirrels shift positions often and exhibit REM-like body twitching (Gaidica and

490 Dantzer, unpublished data), although it is unclear if those movements occur during

491 electrophysiological sleep. We are currently investigating methods to address such questions

492 (Gaidica \& Dantzer, 2020). A common attempt to circumvent these errors is to impose additional

493 sleep-wake rules onto the primary algorithm (Webster et al., 1982). For example, "after at least 4 
494 minutes scored as wake, the next 1 minute scored as sleep is recorded wake," is one of many

495 rules that result in marginal gains in algorithmic performance (Cole et al., 1992). These rules,

496 which have evolved into more complex methods over time, still suffer from being empirical or

497 trained on specific species and conditions, narrowing their applicability.

We did not focus on the source of variation between and within individuals, although our

499 data included both sexes over many years. Investigating sleep-wake patterns by sex (W. Zhang \&

500 Yartsev, 2019), age (Steinmeyer et al., 2010), life-history stage (Wassmer \& Refinetti, 2016), the

501 prevalence of predators (White \& Geluso, 2007), or climatic variation (Helm et al., 2013) are

502 likely fruitful future directions. In red squirrels, day length and mean ambient temperature are

503 positively correlated with overall activity levels, however, we do not have granular data

504 regarding the light at, or temperature inside a given nest (but see Studd et al., 2016). Therefore,

505 we cannot exclude the possibility that microclimates (e.g., the rise and fall of ambient

506 temperature, winter snowfall, cloud cover, nest orientation) could also serve as a strong gate of

507 wakefulness, although, we suspect ambient temperature is a proxy for behavioral requirements of

508 a particular season for red squirrels (Efrat et al., 2019; V. Y. Zhang et al., 2019). We do know

509 that lactating red squirrels select nests with varying insulative qualities to both reduce heat loss

510 and dissipate heat (Guillemette et al., 2009) and the potency of thermal cues should not be

511 underestimated, as they appear to underlie hormonal changes and circadian physiology of

512 heterotherms which determine when to enter and exit hibernation (Lyman, 2014; Williams et al.,

513 2016). Indeed, hibernation itself is difficult to treat with our algorithm without modification.

514 While accelerometers are a good tool to characterize the entrance, maintenance, and exit of

515 hibernation, their data not only require inspection in their raw form but are troublesome to

516 interpret, since hibernation is not sleep (Blanco et al., 2016). Species-specific phenology is likely 
517 a necessary investment for the researcher wishing to apply accelerometry to hibernating animals

518 (Williams et al., 2016) as it can be an ambiguous state of adapted inactivity. In addition,

519 augmenting accelerometers with light or thermal sensors is likely to improve interpretation

520 efforts (Barnes, 1989; Krauchi \& Deboer, 2010; Williams et al., 2011).

\section{Conclusion}

522 Here we present the homeogram to determine sleep-wake patterns from unlabeled accelerometer 523 data. Applying the homeogram to a red squirrel data set, we revealed a mosaic of sleep-wake

524 patterns that are highly plastic and then investigated those patterns using analyses familiar to the

525 sleep or circadian scientist. If applied broadly, the homeogram may help in elucidating the

526 evolutionary history of sleep phenotypes. For example, the phylogenetic history of the red

527 squirrel would predict that they are polyphasic sleepers (Campi \& Krubitzer, 2010). However, as

528 we demonstrate, the sleep-wake patterns — namely in Autumn — appear indifferent from that of

529 humans and other monophasic sleepers, indicating that some animals may exploit a latent ability

530 to engage in briefer sleep episodes (than say, humans) while remaining overtly diurnal based on

531 season or behavioral demands.

532 Although sleep is often appreciated as an emergent quality of wakefulness, we should

533 consider the possibility that wakefulness is an emergent quality of sleep. As such, sleep research

534 requires new tools — such as the homeogram - to progress. 


\section{Acknowledgments}

538 We thank Agnes MacDonald for long-term access to her trapline, and to the Champagne and

539 Aishihik First Nations for allowing us to conduct work on their traditional territory. This

540 research was funded by the Translational Research Institute for Space Health through NASA

541 Cooperative Agreement NNX16AO69A, grants from the Natural Sciences and Engineering

542 Research Council of Canada (to S.B., J.E.L., A.G.M.), the Northern Scientific Training Program

543 (to students of S.B., J.E.L., A.G.M.), the W. Garfield Weston Foundation, and the USA National

544 Science Foundation (IOS-1749627 to B.D).

\section{Author's Contributions}

546 MG developed the methodology, performed the analyses, and wrote the supporting sections of

547 the manuscript with assistance from BD. WG assisted with data processing. BD, EKS, and AEW

548 performed data collection. All other authors provided resources to enable data collection and

549 performance site availability/access as well as provided feedback.

\section{Data Availability}

551 All data will be available on Figshare. 


\section{Supplementary Material}

\section{Data Overview}

555 Data Collection. Between 2014 and 2020, we collected accelerometer data from 218 squirrels

556 over 345 unique recording sessions as part of the Kluane Red Squirrel Project located in Yukon,

557 Canada (60 45' 16.0344", -137 30' 42.4074"). Accelerometers (models Axy2/Axy3/Axy4) were

558 obtained from Technosmart Europe and weighed about 4 grams before packaging into a collar

559 ( $\sim 1.7 \%$ of body mass: Studd et al., 2020). Red squirrels weighed roughly 250 grams. Collars

560 were mounted ventrally (when only the accelerometer was fitted) or dorsally when a VHF radio

561 transmitter was added (model PD-2C, Holohil Systems Limited, Carp, Ontario, Canada; 4 g).

562 Squirrels were captured by live-trapping and briefly handled in a canvas bag to place

563 accelerometer collars on the squirrels using established methods (Dantzer et al., 2020). Each

564 squirrel is permanently and uniquely marked with metal ear tags, enabling individual

565 identification, and the identity, sex, reproductive condition, and body mass of the squirrel was

566 recorded each time it was captured. Further details on the study area and general data collection

567 methods are provided in Dantzer et al. (2020) and collar design is provided in Studd et al. (2019).

568 Data inclusion. Every recording session was manually reviewed for recording quality and

569 questionable data/devices were removed from the analyses. All females that were lactating, pre-

570 pregnant, or pregnant were excluded. Any recording with less than a day of data (1440 minutes)

571 was excluded. 
A

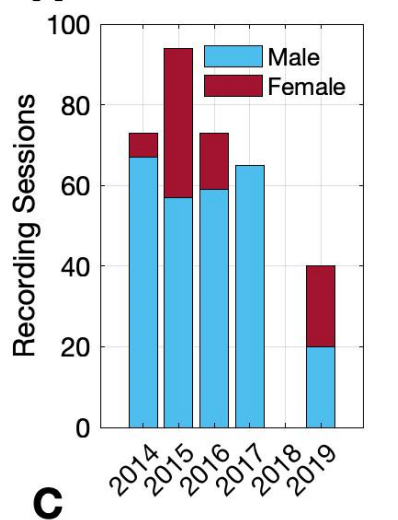

B
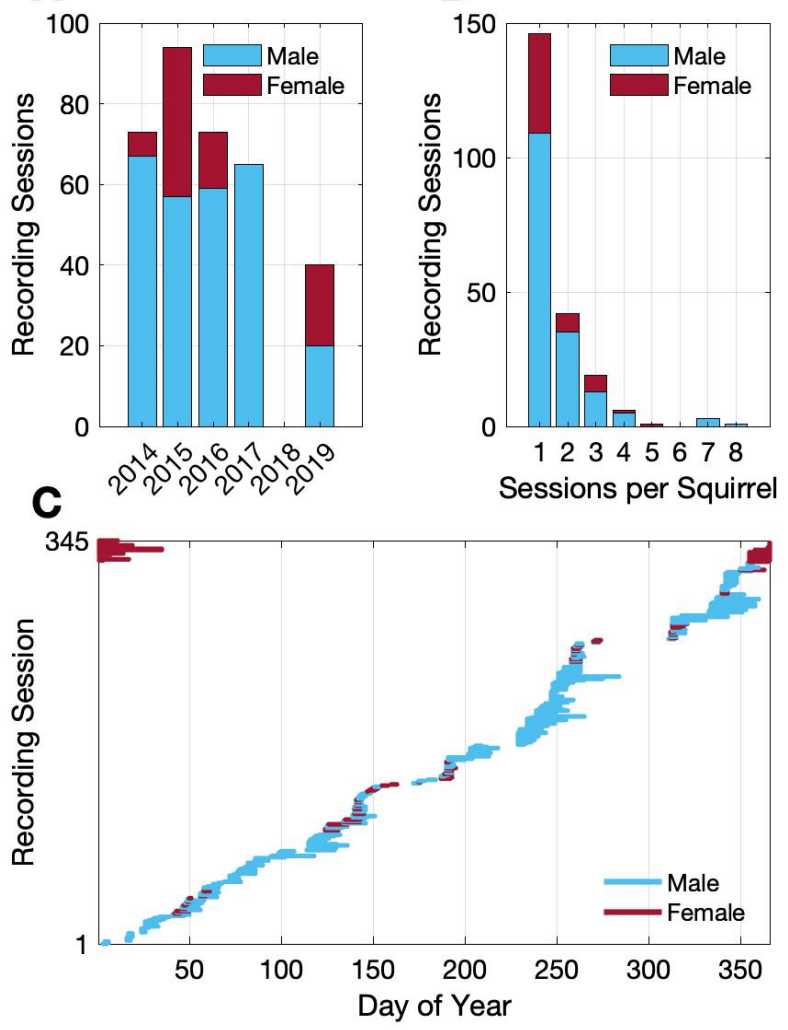

Figure S1. Data Overview. (A) Recording sessions by year (268 male, 77 female). Lactating and pregnant females are not present in these data. (B) Number of recording sessions that are from the same squirrel ( $\mathrm{n}=218$ total squirrels). For example, the same squirrel may have been recorded in 2016 and 2017, contributing to the magnitude of the bar above x-axis '2'. (C) Recording duration for each recording session ( $\mathrm{n}=345$ total), sorted by start day. 


\section{Mast vs. Non-Mast Sleep Statistics}

575 Table S1. Sleep statistics for North American red squirrels in Yukon, Canada derived from

576 homeogram using accelerometry data from only non-mast years $(2015,2016,2017)$ and mast

577 years $(2014,2019)$.

\section{Non-Mast Year}

\begin{tabular}{|c|c|c|c|c|c|}
\hline & Winter & Spring & Summer & Autumn & All \\
\hline Day Length (hrs.) & $6.57 \pm 0.82$ & $12.07 \pm 2.52$ & $18.20 \pm 0.82$ & $12.74 \pm 2.46$ & 12 \\
\hline Sleep per day (hrs.) & $10.49 \pm 1.90$ & $9.32 \pm 2.41$ & $8.30 \pm 1.88$ & $8.95 \pm 1.61$ & $9.66 \pm 2.15$ \\
\hline Sleep in daylight (hrs.) & $0.72 \pm 0.86$ & $1.57 \pm 1.73$ & $3.21 \pm 1.87$ & $1.13 \pm 1.29$ & $1.34 \pm 1.59$ \\
\hline Sleep in darkness (hrs.) & $9.76 \pm 1.82$ & $7.75 \pm 1.73$ & $5.08 \pm 0.98$ & $7.82 \pm 1.09$ & $8.31 \pm 2.28$ \\
\hline Total sleep transitions & $28 \pm 7$ & $22 \pm 8$ & $17 \pm 7$ & $16 \pm 6$ & $23 \pm 9$ \\
\hline Sleep transitions in daylight & $3 \pm 3$ & $6 \pm 4$ & $11 \pm 5$ & $5 \pm 4$ & $5 \pm 5$ \\
\hline Sleep transitions in darkness & $26 \pm 6$ & $17 \pm 8$ & $6 \pm 4$ & $11 \pm 5$ & $18 \pm 9$ \\
\hline
\end{tabular}

\section{Mast Year}

\section{Winter}

Day Length (hrs.)

Sleep per day (hrs.)

Sleep in daylight (hrs.)

Sleep in darkness (hrs.)

Total sleep transitions

Sleep transitions in daylight

Sleep transitions in darkness
$6.57 \pm 0.82$

$\mathrm{NaN} \pm \mathrm{NaN}$

$\mathrm{NaN} \pm \mathrm{NaN}$

$\mathrm{NaN} \pm \mathrm{NaN}$

$\mathrm{NaN} \pm \mathrm{NaN}$

$\mathrm{NaN} \pm \mathrm{NaN}$

$\mathrm{NaN} \pm \mathrm{NaN}$

\section{Spring}

$12.07 \pm 2.52$

$10.19 \pm 1.60$

$2.29 \pm 1.50$

$7.90 \pm 1.82$

$26 \pm 7$

$7 \pm 4$

$19 \pm 7$
Summer

$18.20 \pm 0.82$

$8.83 \pm 2.05$

$4.47 \pm 2.01$

$4.36 \pm 1.06$

$20 \pm 7$

$13 \pm 6$

$7 \pm 4$
Autumn

All

$2.74 \pm 2.46$

12

$8.50 \pm 1.75$

$9.05 \pm 1.98$

$0.71 \pm 1.68$

$2.95 \pm 2.44$

$7.79 \pm 1.38$

$6.10 \pm 2.21$

$13 \pm 6$

$19 \pm 8$

$3 \pm 5$

$9 \pm 7$

$10 \pm 4$

$10 \pm 7$ 


\section{Linear Mixed Effects Regression Tables}

581 Table S2. Are there differences in total sleep time? Results from linear mixed-effects models 582 followed by pairwise comparisons to examine if total sleep time varied according to sex or 583 season.

\section{Total Sleep Time}

\begin{tabular}{lccc} 
Predictors & Estimates & $C I$ & $p$ \\
\hline (Intercept) & 0.44 & $0.43-0.44$ & $<\mathbf{0 . 0 0 1}$ \\
Sex (ref = male) & -0.01 & $-0.02-0.00$ & 0.135 \\
Spring (ref = Winter) & -0.03 & $-0.04--0.02$ & $<\mathbf{0 . 0 0 1}$ \\
Summer (ref = Winter) & -0.07 & $-0.08--0.06$ & $<\mathbf{0 . 0 0 1}$ \\
Autumn (ref = Winter) & -0.06 & $-0.07--0.05$ & $<\mathbf{0 . 0 0 1}$
\end{tabular}

\section{Random Effects}

\begin{tabular}{ll}
$\sigma^{2}$ & 0.00 \\
$\tau_{00}$ squirrelld & 0.00 \\
ICC & 0.08 \\
$\mathrm{~N}_{\text {squirrelld }}$ & 218 \\
\hline Observations & 345 \\
Marginal $\mathrm{R}^{2} /$ Conditional $\mathrm{R}^{2}$ & $0.404 / 0.451$
\end{tabular}

584

\section{Pairwise Differences}

\begin{tabular}{lccccc} 
Pair & Estimate & $S E$ & $d f$ & t.ratio & $P$ \\
\hline Winter-Spring & 0.03110 & 0.00509 & 340 & 6.106 & $<\mathbf{0 . 0 0 1}$ \\
Winter-Summer & 0.06724 & 0.00531 & 322 & 12.660 & $<\mathbf{0 . 0 0 1}$ \\
Winter-Autumn & 0.06061 & 0.00493 & 332 & 12.294 & $<\mathbf{0 . 0 0 1}$ \\
Spring-Summer & 0.03614 & 0.00545 & 315 & 6.635 & $<\mathbf{0 . 0 0 1}$ \\
Spring-Autumn & 0.02952 & 0.00511 & 339 & 5.777 & $<\mathbf{0 . 0 0 1}$ \\
Summer-Autumn & 0.00662 & 0.00512 & 305 & -1.295 & 0.5671
\end{tabular}


588 Table S3. Are there differences in the time slept inside the nest? Results from linear mixed589 effects models followed by pairwise comparisons to examine if sleep time inside the nest varied 590 according to sex or season.

\begin{tabular}{lccc}
\hline \hline & \multicolumn{3}{c}{ Sleep In-Nest } \\
Predictors & Estimates & $C I$ & $p$ \\
\hline (Intercept) & 0.43 & $0.42-0.44$ & $<\mathbf{0 . 0 0 1}$ \\
Sex (ref = male) & -0.01 & $-0.02--0.00$ & $\mathbf{0 . 0 2 5}$ \\
Spring (ref = Winter) & -0.04 & $-0.05--0.03$ & $<\mathbf{0 . 0 0 1}$ \\
Summer (ref = Winter) & -0.08 & $-0.09--0.07$ & $<\mathbf{0 . 0 0 1}$ \\
Autumn (ref = Winter) & -0.07 & $-0.08--0.06$ & $<\mathbf{0 . 0 0 1}$
\end{tabular}

\section{Random Effects}

\begin{tabular}{ll}
$\sigma^{2}$ & 0.00 \\
$\tau_{00}$ squirrelld & 0.00 \\
ICC & 0.09 \\
$\mathrm{~N}_{\text {squirrelld }}$ & 218 \\
\hline Observations & 345 \\
Marginal $\mathrm{R}^{2} /$ Conditional $\mathrm{R}^{2}$ & $0.419 / 0.469$
\end{tabular}

\section{Pairwise Differences}

\begin{tabular}{lccccc} 
Pair & Estimate & $S E$ & $d f$ & t.ratio & $P$ \\
\hline Winter-Spring & 0.03855 & 0.00598 & 340 & 6.451 & $<\mathbf{0 . 0 0 1}$ \\
Winter-Summer & 0.08066 & 0.00624 & 322 & 12.923 & $<\mathbf{0 . 0 0 1}$ \\
Winter-Autumn & 0.07221 & 0.00578 & 332 & 12.488 & $<\mathbf{0 . 0 0 1}$ \\
Spring-Summer & 0.04211 & 0.00640 & 315 & 6.683 & $<\mathbf{0 . 0 0 1}$ \\
Spring-Autumn & 0.03366 & 0.00599 & 339 & 5.616 & $<\mathbf{0 . 0 0 1}$ \\
Summer-Autumn & 0.00845 & 0.00601 & 305 & -1.405 & 0.4972
\end{tabular}


594 Table S4. Are there differences in the time slept outside the nest? Results from linear mixed595 effects models followed by pairwise comparisons to examine if sleep time outside the nest varied 596 according to sex or season.

\section{Sleep Out of Nest}

\begin{tabular}{lccc} 
Predictors & Estimates & $C I$ & $p$ \\
\hline (Intercept) & 0.01 & $0.00-0.02$ & $\mathbf{0 . 0 0 1}$ \\
Sex (ref = male) & 0.01 & $-0.00-0.01$ & 0.149 \\
Spring (ref = Winter) & 0.01 & $-0.00-0.01$ & 0.081 \\
Summer (ref = Winter) & 0.01 & $0.01-0.02$ & $\mathbf{0 . 0 0 1}$ \\
Autumn (ref = Winter) & 0.01 & $0.00-0.02$ & $\mathbf{0 . 0 0 3}$
\end{tabular}

\section{Random Effects}

\begin{tabular}{ll}
$\sigma^{2}$ & 0.00 \\
$\tau_{00}$ squirrelld & 0.00 \\
$\mathrm{ICC}$ & 0.05 \\
$\mathrm{~N}_{\text {squirrelld }}$ & 218 \\
\hline Observations & 345 \\
Marginal $\mathrm{R}^{2} /$ Conditional $\mathrm{R}^{2}$ & $0.049 / 0.095$
\end{tabular}

\section{Pairwise Differences}

\begin{tabular}{lccccc} 
Pair & Estimate & $S E$ & $d f$ & t.ratio & $P$ \\
\hline Winter-Spring & -0.00699 & 0.00401 & 340 & -1.743 & 0.3031 \\
Winter-Summer & -0.01338 & 0.00417 & 319 & -3.212 & $\mathbf{0 . 0 0 7 9}$ \\
Winter-Autumn & -0.01136 & 0.00389 & 334 & -2.921 & $\mathbf{0 . 0 1 9 4}$ \\
Spring-Summer & -0.00639 & 0.00427 & 309 & -1.498 & 0.4402 \\
Spring-Autumn & -0.00437 & 0.00402 & 340 & -1.087 & 0.6976 \\
Summer-Autumn & 0.00202 & 0.00401 & 297 & 0.504 & 0.9581
\end{tabular}


600 Table S5. Are there differences in the proportion of time slept in the nest? Results from linear 601 mixed-effects model to examine if proportion of sleep (sleep in-nest / total sleep) varied 602 according to sex or season.

Proportion of Sleep In-Nest

\begin{tabular}{lccc} 
Predictors & Estimates & $C I$ & $p$ \\
\hline (Intercept) & 0.52 & $0.51-0.54$ & $<\mathbf{0 . 0 0 1}$ \\
Sex (ref = male) & -0.01 & $-0.03-0.01$ & 0.206 \\
Spring (ref = Winter) & 0.06 & $0.04-0.08$ & $<\mathbf{0 . 0 0 1}$ \\
Summer (ref = Winter) & 0.07 & $0.05-0.09$ & $<\mathbf{0 . 0 0 1}$ \\
Autumn (ref = Winter) & 0.14 & $0.12-0.16$ & $<\mathbf{0 . 0 0 1}$
\end{tabular}

\section{Random Effects}

\begin{tabular}{ll}
$\sigma^{2}$ & 0.00 \\
$\tau_{00}$ squirrelld & 0.00 \\
$\mathrm{ICC}$ & 0.15 \\
$\mathrm{~N}_{\text {squirrelld }}$ & 218 \\
\hline Observations & 345 \\
Marginal $\mathrm{R}^{2} /$ Conditional $\mathrm{R}^{2}$ & $0.349 / 0.449$
\end{tabular}

603

604

\section{Pairwise Differences}

\begin{tabular}{lccccc} 
Pair & Estimate & $S E$ & $d f$ & t.ratio & $P$ \\
\hline Winter-Spring & -0.0593 & 0.0104 & 338 & -5.710 & $<\mathbf{0 . 0 0 1}$ \\
Winter-Summer & -0.0702 & 0.0109 & 327 & -6.419 & $<\mathbf{0 . 0 0 1}$ \\
Winter-Autumn & -0.1375 & 0.0100 & 327 & -13.745 & $<\mathbf{0 . 0 0 1}$ \\
Spring-Summer & -0.0109 & 0.0112 & 324 & -0.971 & 0.7663 \\
Spring-Autumn & -0.0782 & 0.0104 & 335 & -7.516 & $<\mathbf{0 . 0 0 1}$ \\
Summer-Autumn & -0.0673 & 0.0106 & 317 & -6.366 & $<\mathbf{0 . 0 0 1}$
\end{tabular}


606 Table S6. Are there interaction effects between season and mast that change the proportion of

607 time slept in the nest? Results from linear mixed-effects models followed by pairwise

608 comparisons to examine if proportion of sleep (sleep in-nest / total sleep) varied according to sex

609 or season.

\begin{tabular}{lccc}
\hline \hline & \multicolumn{3}{c}{ Proportion of Sleep In-Nest } \\
Predictors & Estimates & $C I$ & $p$ \\
\hline (Intercept) & 0.57 & $0.55-0.60$ & $<\mathbf{0 . 0 0 1}$ \\
Sex (ref = male) & -0.02 & $-0.04-0.01$ & 0.152 \\
Summer (ref = Winter) & 0.02 & $-0.01-0.05$ & 0.238 \\
Autumn (ref = Winter) & 0.06 & $0.04-0.09$ & $<\mathbf{0 . 0 0 1}$ \\
Mast (ref = Mast) & 0.01 & $-0.02-0.04$ & 0.445 \\
Summer * Mast & -0.01 & $-0.06-0.03$ & 0.571 \\
Autumn * Mast & 0.07 & $0.03-0.12$ & $\mathbf{0 . 0 0 1}$
\end{tabular}

\section{Random Effects}

\begin{tabular}{ll}
$\sigma^{2}$ & 0.00 \\
$\tau_{00 \text { squirrelld }}$ & 0.00 \\
ICC & 0.25 \\
$\mathrm{~N}_{\text {squirrelld }}$ & 179 \\
\hline Observations & 261 \\
Marginal $\mathrm{R}^{2} /$ Conditional $\mathrm{R}^{2}$ & $0.243 / 0.436$
\end{tabular}

Pairwise Differences

Pair

Spring nMast - Spring Mast

Spring nMast - Summer nMast

Spring nMast - Summer Mast

Spring nMast - Autumn nMast

Spring nMast - Autumn Mast

Spring Mast - Summer nMast

Spring Mast - Summer Mast

Spring Mast - Autumn nMast

Spring Mast - Autumn Mast

Summer nMast - Summer Mast

$\begin{array}{ccccc}\text { Estimate } & S E & d f & \text { t.ratio } & P \\ -0.012467 & 0.0156 & 251 & -0.798 & 0.9676 \\ -0.015648 & 0.0169 & 255 & -0.924 & 0.9400 \\ -0.012467 & 0.00156 & 245 & -0.957 & 0.9307 \\ -0.012467 & 0.00156 & 237 & -4.407 & <\mathbf{0 . 0 0 1} \\ -0.012467 & 0.00156 & 215 & -8.230 & <\mathbf{0 . 0 0 1} \\ -0.012467 & 0.00156 & 238 & -0.181 & 1.0000 \\ -0.012467 & 0.00156 & 219 & -0.145 & 1.0000 \\ -0.012467 & 0.00156 & 231 & -3.193 & \mathbf{0 . 0 1 9 7} \\ -0.012467 & 0.00156 & 248 & -7.238 & <\mathbf{0 . 0 0 1} \\ -0.012467 & 0.00156 & 252 & 0.050 & 1.0000\end{array}$


Summer nMast - Autumn nMast

Summer nMast - Autumn Mast

Summer Mast - Autumn nMast

Summer Mast - Autumn Mast
Autumn nMast - Autumn Mast

$\begin{array}{lllll}-0.012467 & 0.00156 & 248 & -2.717 & 0.0755 \\ -0.012467 & 0.00156 & 246 & -6.603 & <\mathbf{0 . 0 0 1} \\ -0.012467 & 0.00156 & 225 & -3.103 & \mathbf{0 . 0 2 6 0} \\ -0.012467 & 0.00156 & 252 & -7.159 & <\mathbf{0 . 0 0 1} \\ -0.012467 & 0.00156 & 207 & -5.195 & <\mathbf{0 . 0 0 1}\end{array}$

612 


\section{Comparing Homeogram to Conventional Sleep-wake Algorithm}

614 We obtained 7 days of human axy data (with ambient light intensity) from Vincent van Hees

615 (https://accelting.com/) and reshaped it to exactly match ODBA of our squirrel data. We applied

616 the Sadeh algorithm (Sadeh et al., 1994) by modifying the empirically-determined first term,

617 which draws a threshold for sleep-wake classification. In brief, the Sadeh algorithm is formed as,

$618 P($ sleep $)=$ Threshold - Weighted parameters applied to actigraphy, where $P($ sleep $)>0=$ sleep.

619 In Figure S2, run our homeogram algorithm alongside the Sadeh algorithm and find 95.54\%

620 agreement. Where the algorithms disagree appears isolated to spurious deviations in the

621 accelerometer data. Since the homeogram has a circadian base filter, these deviations these

622 deviations are weighted towards 'asleep' during the primary sleep period, and towards 'awake'

623 during the primary wake period. In other words, the homeogram adds circadian gravity for

624 spurious data that may not represent a behaviorally relevant shift in movement/behavior. Sadeh-

625 like algorithms or simply increasing the smoothing factor lack this feature, as they are highly

626 localized, whereas the homeogram has a global context. Importantly, the Sadeh algorithm

627 requires 5 terms that must be determined a priori-making it potentially useful for controlled

628 animals labelled data is available — whereas the homeogram only requires 1, which is optional. 

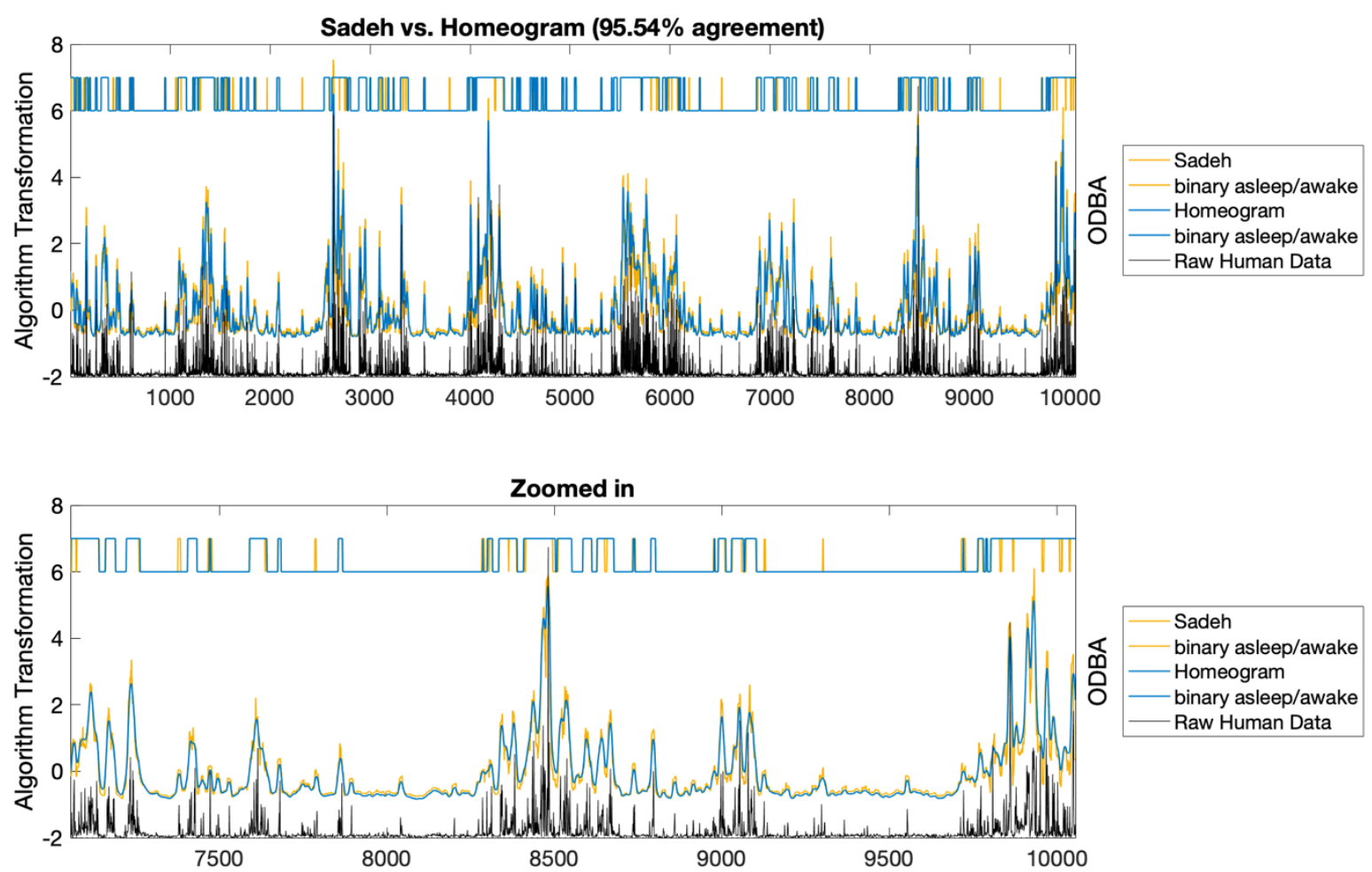

Figure S2. Homeogram agreement with conventional algorithm.

(Top) Sadeh algorithm (yellow) and Homeogram (blue) methods applied to 7 days of human actigraphy (black, right ODBA axis). The algorithmic transformation is shown in analog form (left y-axis) and then binarized when the probability for asleep state is greater than 0 , offset from the left-axis between values 6-7. (Bottom) Zoomed in version. 
630 Bibliography

631 Achermann, P., \& Borbély, A. A. (2011). Sleep Homeostasis and Models of Sleep Regulation. In

632 Principles and Practice of Sleep Medicine (pp. 431-444). Elsevier.

633 https://doi.org/10.1016/B978-1-4160-6645-3.00037-2

634 Altini, M., \& Kinnunen, H. (2021). The Promise of Sleep: A Multi-Sensor Approach for

635 Accurate Sleep Stage Detection Using the Oura Ring. Sensors, 21(13), 4302.

636

Anafi, R. C., Kayser, M. S., \& Raizen, D. M. (2019). Exploring phylogeny to find the function of sleep. Nature Reviews Neuroscience, 20(2), 109-116. https://doi.org/10.1038/s41583018-0098-9

Ancoli-Israel, S., Cole, R., Alessi, C., Chambers, M., Moorcroft, W., \& Pollak, C. P. (2003). The Role of Actigraphy in the Study of Sleep and Circadian Rhythms. Sleep, 26(3), 342-392.

Aulsebrook, A. E., Jones, T. M., Rattenborg, N. C., Roth, T. C., \& Lesku, J. A. (2016). Sleep Ecophysiology: Integrating Neuroscience and Ecology. Trends in Ecology \& Evolution, 31(8), 590-599. https://doi.org/10.1016/j.tree.2016.05.004

Bedford, N. L., Gable, J. T., Hu, C. K., Wooldridge, T. B., Sokolov, N. A., Lassance, J.-M., \& Hoekstra, H. E. (2021). Automated tracking reveals the social network of beach mice and their burrows. BioRxiv, 2021.08.07.455531. https://doi.org/10.1101/2021.08.07.455531

651 Blanco, M. B., Dausmann, K. H., Faherty, S. L., Klopfer, P., Krystal, A. D., Schopler, R., \& Yoder, A. D. (2016). Hibernation in a primate: Does sleep occur? Royal Society Open 
Science, 3(8), 160282. https://doi.org/10.1098/rsos.160282

654 Bonnet, M. H. (1987). Sleep Restoration as a Function of Periodic Awakening, Movement, or Electroencephalographic Change. Sleep, 10(4), 364-373.

Borbély, A. A. (1982). A two process model of sleep regulation. Human Neurobiology, 1(3), 195-204.

Boutin, S., Wauters, L. A., McAdam, A. G., Humphries, M. M., Tosi, G., \& Dhondt, A. A. (2006). Anticipatory Reproduction and Population Growth in Seed Predators. Science, 314(5807), 1928-1930. https://doi.org/10.1126/science.1135520

Brigham, R. M., \& Geiser, F. (2012). Do red squirrels (Tamiasciurus hudsonicus) use daily

Brown, D. D., Kays, R., Wikelski, M., Wilson, R., \& Klimley, A. (2013). Observing the unwatchable through acceleration logging of animal behavior. Animal Biotelemetry, 1(1), 20. https://doi.org/10.1186/2050-3385-1-20 torpor during winter? Écoscience, 19(2), 127-132. https://doi.org/10.2980/19-2-3464

Broughton, R. J. (1998). SCN controlled circadian arousal and the afternoon "nap zone.” Sleep 
676 Campi, K. L., \& Krubitzer, L. (2010). Comparative studies of diurnal and nocturnal rodents: Differences in lifestyle result in alterations in cortical field size and number. The Journal of Comparative Neurology, 518(22), 4491-4512. https://doi.org/10.1002/cne.22466

679 Cano, G., Mochizuki, T., \& Saper, C. B. (2008). Neural Circuitry of Stress-Induced Insomnia in Rats. Journal of Neuroscience, 28(40), 10167-10184. https://doi.org/10.1523/JNEUROSCI.1809-08.2008

Capellini, I., Barton, R. A., McNamara, P., Preston, B. T., \& Nunn, C. L. (2008). 5646.2008.00392.x

Capellini, I., Nunn, C. L., McNamara, P., Preston, B. T., \& Barton, R. A. (2008). Energetic constraints, not predation, influence the evolution of sleep patterning in mammals. Functional Ecology, 22(5), 847-853. https://doi.org/10.1111/j.1365-2435.2008.01449.x Sleep Medicine (pp. 16-26). Elsevier. https://doi.org/10.1016/B978-1-4160-6645-

Cerri, M., \& Amici, R. (2021). Thermoregulation and Sleep: Functional Interaction and Central Nervous Control. In Comprehensive Physiology (pp. 1591-1604). American Cancer Society. https://doi.org/10.1002/cphy.c140012 in accelerometer data. Ecology and Evolution, 6(3), 727-741. https://doi.org/10.1002/ece3.1914 
699 Cole, R. J., Kripke, D. F., Gruen, W., Mullaney, D. J., \& Gillin, J. C. (1992). Automatic Sleep/Wake Identification From Wrist Activity. Sleep, 15(5), 461-469. https://doi.org/10.1093/sleep/15.5.461

Cornelis, J., Smets, E., \& Van Hoof, C. (2019). Accelerometer-based Sleep/Wake Detection in an Ambulatory Environment: Proceedings of the 12th International Joint Conference on

Dallman, M. F., la Fleur, S. E., Pecoraro, N. C., Gomez, F., Houshyar, H., \& Akana, S. F. (2004). Minireview: Glucocorticoids_Food Intake, Abdominal Obesity, and Wealthy Nations in 2004. Endocrinology, 145(6), 2633-2638. https://doi.org/10.1210/en.2004-

Dantzer, B., McAdam, A. G., Humphries, M. M., Lane, J. E., \& Boutin, S. (2020). Decoupling experiments: Insights from the steward who sits in the shadow of its tail, the North American red squirrel. Journal of Animal Ecology, 89(11), 2397-2414. https://doi.org/10.1111/1365-2656.13341

Dantzer, B., Santicchia, F., van Kesteren, F., Palme, R., Martinoli, A., \& Wauters, L. A. (2016).

Dantzer, B., Newman, A. E. M., Boonstra, R., Palme, R., Boutin, S., Humphries, M. M., \& Measurement of fecal glucocorticoid metabolite levels in Eurasian red squirrels ( Sciurus vulgaris ): Effects of captivity, sex, reproductive condition, and season. Journal of 
Mammalogy, 97(5), 1385-1398. https://doi.org/10.1093/jmammal/gyw095

723

724

725

726

727

728

Debellemaniere, E., Chambon, S., Pinaud, C., Thorey, V., Dehaene, D., Léger, D., Chennaoui, M., Arnal, P. J., \& Galtier, M. N. (2018). Performance of an Ambulatory Dry-EEG Device for Auditory Closed-Loop Stimulation of Sleep Slow Oscillations in the Home Environment. Frontiers in Human Neuroscience, 12, 88. https://doi.org/10.3389/fnhum.2018.00088

Deboer, T. (2018). Sleep homeostasis and the circadian clock: Do the circadian pacemaker and the sleep homeostat influence each other's functioning? Neurobiology of Sleep and Circadian Rhythms, 5, 68-77. https://doi.org/10.1016/j.nbscr.2018.02.003

Dekking, M. (Ed.). (2005). A modern introduction to probability and statistics: Understanding why and how. Springer.

Dimanico, M. M., Klaassen, A.-L., Wang, J., Kaeser, M., Harvey, M., Rasch, B., \& Rainer, G. (2021). Aspects of tree shrew consolidated sleep structure resemble human sleep. Communications Biology, 4(1), 722. https://doi.org/10.1038/s42003-021-02234-7

Dolezal, B. A., Neufeld, E. V., Boland, D. M., Martin, J. L., \& Cooper, C. B. (2017). Interrelationship between Sleep and Exercise: A Systematic Review. Advances in Preventive Medicine, 2017. https://doi.org/10.1155/2017/1364387

Dowse, H. B. (2009). Chapter 6 Analyses for Physiological and Behavioral Rhythmicity. In Methods in Enzymology (Vol. 454, pp. 141-174). Elsevier. https://doi.org/10.1016/S0076-6879(08)03806-8

Eban-Rothschild, A., Giardino, W. J., \& de Lecea, L. (2017). To sleep or not to sleep: Neuronal and ecological insights. Current Opinion in Neurobiology, 44, 132-138. https://doi.org/10.1016/j.conb.2017.04.010 
Efrat, R., Harel, R., Alexandrou, O., Catsadorakis, G., \& Nathan, R. (2019). Seasonal differences in energy expenditure, flight characteristics and spatial utilization of Dalmatian Pelicans Pelecanus crispus in Greece. Ibis, 161(2), 415-427. https://doi.org/10.1111/ibi.12628

Enomoto, M., Endo, T., Suenaga, K., Miura, N., Nakano, Y., Kohtoh, S., Taguchi, Y., Aritake, S., Higuchi, S., Matsuura, M., Takahashi, K., \& Mishima, K. (2009). Newly developed waist actigraphy and its sleep/wake scoring algorithm. Sleep and Biological Rhythms,

Ephron, H. S., \& Carrington, P. (1966). Rapid eye movement sleep and cortical homeostasis. Psychological Review, 73(6), 500-526. https://doi.org/10.1037/h0023888

Fisher, D. N., Wilson, A. J., Boutin, S., Dantzer, B., Lane, J. E., Coltman, D. W., Gorrell, J. C., \& McAdam, A. G. (2019). Social effects of territorial neighbours on the timing of spring breeding in North American red squirrels. Journal of Evolutionary Biology, 32(6), 559-

Fletcher, Q. E., Boutin, S., Lane, J. E., LaMontagne, J. M., McAdam, A. G., Krebs, C. J., \& Humphries, M. M. (2010). The functional response of a hoarding seed predator to mast

Fletcher, Q. E., Landry-Cuerrier, M., Boutin, S., McAdam, A. G., Speakman, J. R., \& Humphries, M. M. (2013). Reproductive timing and reliance on hoarded capital resources by lactating red squirrels. Oecologia, 173(4), 1203-1215. https://doi.org/10.1007/s00442-

Fletcher, Q. E., Speakman, J. R., Boutin, S., McAdam, A. G., Woods, S. B., \& Humphries, M. 
squirrels. Functional Ecology, 26(3), 677-687. https://doi.org/10.1111/j.13652435.2012.01975.x

770

771

772

773

774

775

776

777

778

779

780

781

782

783

784

785

786

787

788

789

790

Gaidica, M., \& Dantzer, B. (2020). Quantifying the Autonomic Response to Stressors-One Way to Expand the Definition of "Stress" in Animals. Integrative and Comparative Biology, 60(1), 113-125. https://doi.org/10.1093/icb/icaa009

Gibson, E. M., Williams, W. P., \& Kriegsfeld, L. J. (2009). Aging in the circadian system: Considerations for health, disease prevention and longevity. Experimental Gerontology, 44(1-2), 51-56. https://doi.org/10.1016/j.exger.2008.05.007

Gravett, N., Bhagwandin, A., Sutcliffe, R., Landen, K., Chase, M. J., Lyamin, O. I., Siegel, J. M., \& Manger, P. R. (2017). Inactivity/sleep in two wild free-roaming African elephant matriarchs - Does large body size make elephants the shortest mammalian sleepers? PLOS ONE, 12(3), e0171903. https://doi.org/10.1371/journal.pone.0171903

Guillemette, C. U., Fletcher, Q. E., Boutin, S., Hodges, R. M., McAdam, A. G., \& Humphries, M. M. (2009). Lactating red squirrels experiencing high heat load occupy less insulated nests. Biology Letters, 5(2), 166-168. https://doi.org/10.1098/rsbl.2008.0592

Hammond, T. T., Springthorpe, D., Walsh, R. E., \& Berg-Kirkpatrick, T. (2016). Using accelerometers to remotely and automatically characterize behavior in small animals. The Journal of Experimental Biology, 219(11), 1618-1624. https://doi.org/10.1242/jeb.136135

Harding, E. C., Franks, N. P., \& Wisden, W. (2020). Sleep and thermoregulation. Current Opinion in Physiology, 15, 7-13. https://doi.org/10.1016/j.cophys.2019.11.008

Helm, B., Ben-Shlomo, R., Sheriff, M. J., Hut, R. A., Foster, R., Barnes, B. M., \& Dominoni, D. (2013). Annual rhythms that underlie phenology: Biological time-keeping meets 
environmental change. Proceedings of the Royal Society B: Biological Sciences, 280(1765), 20130016. https://doi.org/10.1098/rspb.2013.0016

Jones, D., Gershon, S., Sitaram, N., \& Keshavan, M. (1987). Sleep and Depression. Psychopathology, 20(Suppl. 1), 20-31. https://doi.org/10.1159/000284520

Kelly, D. (1994). The evolutionary ecology of mast seeding. Trends in Ecology \& Evolution, 9(12), 465-470. https://doi.org/10.1016/0169-5347(94)90310-7

Kenna, S. (2017, August 10). Why Can We Do Things In Our Sleep And Not Remember Them? Huffington Post. https://www.huffingtonpost.com.au/2017/08/10/why-can-we-do-things-

Khanh, P. C. P., Dinh Chinh, N., Cham, T. T., Vui, P. T., \& Tan, T. D. (2016). Classification of cow behavior using 3-DOF accelerometer and decision tree algorithm. 2016 International Conference on Biomedical Engineering (BME-HUST), 45-50.

Kimoff, R. J. (1996). Sleep fragmentation in obstructive sleep apnea. Sleep, 19(9 Suppl), S61-66. https://doi.org/10.1093/sleep/19.supp1_9.s61

Klugh, A. B. (1927). Ecology of the Red Squirrel. Journal of Mammalogy, 8(1), 1. https://doi.org/10.2307/1373393

808 Krauchi, K., \& Deboer, T. (2010). The interrelationship between sleep regulation and thermoregulation. Frontiers in Bioscience (Landmark Edition), 15, 604-625. https://doi.org/10.2741/3636

811 Laposky, A. D., Bass, J., Kohsaka, A., \& Turek, F. W. (2008). Sleep and circadian rhythms: Key components in the regulation of energy metabolism. FEBS Letters, 582(1), 142-151. https://doi.org/10.1016/j.febslet.2007.06.079 
814 Lavie, P. (1986). Ultrashort sleep-waking schedule. III. 'Gates' and 'Forbidden zones' for sleep.

815

816

817

818 Electroencephalography and Clinical Neurophysiology, 63(5), 414-425. https://doi.org/10.1016/0013-4694(86)90123-9

Lesku, J. A., Roth II, T. C., Amlaner, C. J., \& Lima, S. L. (2006). A Phylogenetic Analysis of Sleep Architecture in Mammals: The Integration of Anatomy, Physiology, and Ecology. The American Naturalist, 168(4), 441-453. https://doi.org/10.1086/506973

Lesku, J. A., Roth II, T. C., Rattenborg, N. C., Amlaner, C. J., \& Lima, S. L. (2009). History and future of comparative analyses in sleep research. Neuroscience \& Biobehavioral Reviews, 33(7), 1024-1036. https://doi.org/10.1016/j.neubiorev.2009.04.002

Levine, J. D., Funes, P., Dowse, H. B., \& Hall, J. C. (2002). Signal analysis of behavioral and molecular cycles. BMC Neuroscience, 25.

Lo, C.-C., Amaral, L. A. N., Havlin, S., Ivanov, P. C., Penzel, T., Peter, J.-H., \& Stanley, H. E. (2002). Dynamics of sleep-wake transitions during sleep. Europhysics Letters (EPL), 57(5), 625-631. https://doi.org/10.1209/epl/i2002-00508-7

Lo, C.-C., Chou, T., Penzel, T., Scammell, T. E., Strecker, R. E., Stanley, H. E., \& Ivanov, P. Ch. (2004). Common scale-invariant patterns of sleep-wake transitions across mammalian species. Proceedings of the National Academy of Sciences of the United States of America, 101(50), 17545-17548. https://doi.org/10.1073/pnas.0408242101

Loftus, J., Harel, R., Nuñez, C., \& Crofoot, M. (2021). Ecological and social pressures interfere with homeostatic sleep regulation in the wild [Preprint]. Animal Behavior and Cognition. https://doi.org/10.1101/2021.09.26.461870

Louie, K., \& Wilson, M. A. (2001). Temporally Structured Replay of Awake Hippocampal Ensemble Activity during Rapid Eye Movement Sleep. Neuron, 29(1), 145-156. 
https://doi.org/10.1016/S0896-6273(01)00186-6

838 Lutz, N. D., Wolf, I., Hübner, S., Born, J., \& Rauss, K. (2018). Sleep Strengthens Predictive Sequence Coding. Journal of Neuroscience, 38(42), 8989-9000. https://doi.org/10.1523/JNEUROSCI.1352-18.2018

Lyman, C. P. (2014). Hibernation and Torpor in Mammals and Birds. Elsevier Science. http://public.eblib.com/choice/publicfullrecord.aspx?p=1155691

Massot, B., Arthaud, S., Barrillot, B., Roux, J., Ungurean, G., Luppi, P.-H., Rattenborg, N. C., \&

McAdam, A. G., Boutin, S., Dantzer, B., \& Lane, J. E. (2019). Seed Masting Causes

Mckenna, J. T., Cordeira, J. W., Christie, M. A., Tartar, J. L., Mccoy, J. G., Lee, E., Mccarley, R. Naturalist, 194(4), 574-589. https://doi.org/10.1086/703743 W., \& Strecker, R. E. (2008). Assessing sleepiness in the rat: A multiple sleep latencies test compared to polysomnographic measures of sleepiness. Journal of Sleep Research, 17(4), 365-375. https://doi.org/10.1111/j.1365-2869.2008.00686.x C. (2020). A validation study of the WHOOP strap against polysomnography to assess sleep. Journal of Sports Sciences, 38(22), 2631-2636. 
https://doi.org/10.1080/02640414.2020.1797448

861 Mistlberger, R. E., \& Rusak, B. (2011). Circadian Rhythms in Mammals. In Principles and Practice of Sleep Medicine (pp. 363-375). Elsevier. https://doi.org/10.1016/B978-1-

Mongrain, V., \& Dumont, M. (2007). Increased Homeostatic Response to Behavioral Sleep Fragmentation in Morning Types Compared to Evening Types. Sleep, 30(6), 773-780.

Naiman, R. (2017). Dreamless: The silent epidemic of REM sleep loss: The silent epidemic of REM sleep loss. Annals of the New York Academy of Sciences, 1406(1), 77-85. https://doi.org/10.1111/nyas.13447

Pandey, A., \& Kar, S. K. (2018). "Rapid Eye Movement sleep deprivation of rat generates ROS in the hepatocytes and makes them more susceptible to oxidative stress" [Preprint]. Molecular Biology. https://doi.org/10.1101/375683

Paquet, J., Kawinska, A., \& Carrier, J. (2007). Wake Detection Capacity of Actigraphy During

Nakazaki, K., Kitamura, S., Motomura, Y., Hida, A., Kamei, Y., Miura, N., \& Mishima, K. (2014). Validity of an algorithm for determining sleep/wake states using a new actigraph. Journal of Physiological Anthropology, 33(1), 31. https://doi.org/10.1186/1880-6805-3331

Pittendrigh, C. S., \& Minis, D. H. (1972). Circadian Systems: Longevity as a Function of 
of Sciences of the United States of America, 69(6), 1537-1539.

884 Ramesh, V., Kaushal, N., \& Gozal, D. (2009). Sleep fragmentation differentially modifies EEG delta power during slow wave sleep in socially isolated and paired mice. Sleep Science,

Rattenborg, N. C., de la Iglesia, H. O., Kempenaers, B., Lesku, J. A., Meerlo, P., \& Scriba, M. F. (2017). Sleep research goes wild: New methods and approaches to investigate the ecology, evolution and functions of sleep. Philosophical Transactions of the Royal Society B: Biological Sciences, 372(1734), 20160251. https://doi.org/10.1098/rstb.2016.0251

Refinetti, R. (2007). Absence of circadian and photoperiodic conservation of energy expenditure in three rodent species. Journal of Comparative Physiology B, 177(3), 309-318. https://doi.org/10.1007/s00360-006-0130-7

Reid, K. J., \& Zee, P. C. (2011). Circadian Disorders of the Sleep-Wake Cycle. In Principles and Practice of Sleep Medicine (pp. 470-482). Elsevier. https://doi.org/10.1016/B978-14160-6645-3.00041-4

Rietveld, W. J., Minors, D. S., \& Waterhouse, J. M. (1993). Circadian Rhythms and Masking:

904 An Overview. Chronobiology International, 10(4), 306-312. https://doi.org/10.1080/07420529309059713

Roth, T. C., Rattenborg, N. C., \& Pravosudov, V. V. (2010). The ecological relevance of sleep: The trade-off between sleep, memory and energy conservation. Philosophical Transactions of the Royal Society B: Biological Sciences, 365(1542), 945-959. https://doi.org/10.1098/rstb.2009.0209 

Animal Behaviour, 20(4), 637-643. https://doi.org/10.1016/S0003-3472(72)80136-2

907

908

909

910

911

912

913

914

915

916

917

918

919

920

921

922

923

924

925

926

927

928

Sadeh, A. (2011). The role and validity of actigraphy in sleep medicine: An update. Sleep Medicine Reviews, 15(4), 259-267. https://doi.org/10.1016/j.smrv.2010.10.001

Sadeh, A., Sharkey, M., \& Carskadon, M. A. (1994). Activity-Based Sleep-Wake Identification: An Empirical Test of Methodological Issues. Sleep, 17(3), 201-207. https://doi.org/10.1093/sleep/17.3.201

Sazonov, E., Sazonova, N., Schuckers, S., Neuman, M., \& Group, C. S. (2004). Activity-based sleep-wake identification in infants. Physiological Measurement, 25(5), 1291-1304. https://doi.org/10.1088/0967-3334/25/5/018

Schmidt, M. H. (2014). The energy allocation function of sleep: A unifying theory of sleep, torpor, and continuous wakefulness. Neuroscience \& Biobehavioral Reviews, 47, 122153. https://doi.org/10.1016/j.neubiorev.2014.08.001

Shepard, E., Wilson, R., Halsey, L., Quintana, F., Gómez Laich, A., Gleiss, A., Liebsch, N., Myers, A., \& Norman, B. (2008). Derivation of body motion via appropriate smoothing of acceleration data. Aquatic Biology, 4, 235-241. https://doi.org/10.3354/ab00104

Shuert, C. R., Pomeroy, P. P., \& Twiss, S. D. (2018). Assessing the utility and limitations of accelerometers and machine learning approaches in classifying behaviour during lactation in a phocid seal. Animal Biotelemetry, 6(1), 14. https://doi.org/10.1186/s40317018-0158-y

Siegel, J. M. (2011). REM Sleep*. In Principles and Practice of Sleep Medicine (pp. 92-111). Elsevier. https://doi.org/10.1016/B978-1-4160-6645-3.00008-6

Steele, M. A., \& Koprowski, J. L. (2003). North American tree squirrels. Smithsonian Institution; Combined Academic. 
929 Steinmeyer, C., Schielzeth, H., Mueller, J. C., \& Kempenaers, B. (2010). Variation in sleep

930 behaviour in free-living blue tits, Cyanistes caeruleus: Effects of sex, age and

931 environment. Animal Behaviour, 80(5), 853-864.

932 https://doi.org/10.1016/j.anbehav.2010.08.005

933 Stepanski, E. J. (2002). The effect of sleep fragmentation on daytime function. Sleep, 25(3),

934 268-276. https://doi.org/10.1093/sleep/25.3.268

935 Stickgold, R., \& Walker, M. P. (Eds.). (2009). The neuroscience of sleep. Academic

$936 \quad$ Press/Elsevier.

937 Strangman, G. E., Ivkovic, V., \& Zhang, Q. (2018). Wearable brain imaging with multimodal

938 physiological monitoring. Journal of Applied Physiology, 124(3), 564-572.

939 https://doi.org/10.1152/japplphysiol.00297.2017

940 Stuber, E. F., Dingemanse, N. J., Kempenaers, B., \& Mueller, J. C. (2015). Sources of

941 intraspecific variation in sleep behaviour of wild great tits. Animal Behaviour, 106, 201-

942 221. https://doi.org/10.1016/j.anbehav.2015.05.025

943 Studd, E. K., Boutin, S., McAdam, A. G., \& Humphries, M. M. (2016). Nest attendance of

944 lactating red squirrels ( Tamiasciurus hudsonicus ): Influences of biological and

945 environmental correlates. Journal of Mammalogy, 97(3), 806-814.

946 https://doi.org/10.1093/jmammal/gyw010

947 Studd, E. K., Landry-Cuerrier, M., Menzies, A. K., Boutin, S., McAdam, A. G., Lane, J. E., \&

948 Humphries, M. M. (2019). Behavioral classification of low-frequency acceleration and

949 temperature data from a free-ranging small mammal. Ecology and Evolution, 9(1), 619-

950 630. https://doi.org/10.1002/ece3.4786

951 Studd, E. K., Menzies, A. K., Siracusa, E. R., Dantzer, B., Lane, J. E., McAdam, A. G., Boutin, 
S., \& Humphries, M. M. (2020). Optimisation of energetic and reproductive gains explains behavioural responses to environmental variation across seasons and years. Ecology Letters, 23(5), 841-850. https://doi.org/10.1111/ele.13494

955 Sulli, G., Manoogian, E. N. C., Taub, P. R., \& Panda, S. (2018). Training the Circadian Clock, Clocking the Drugs, and Drugging the Clock to Prevent, Manage, and Treat Chronic Diseases. Trends in Pharmacological Sciences, 39(9), 812-827.

Tafti, M., Villemin, E., Carlander, B., Besset, A., \& Billiard, M. (1992). Sleep in human https://doi.org/10.1016/j.tips.2018.07.003

Tobler, I. (2011). Phylogeny of Sleep Regulation. In Principles and Practice of Sleep Medicine (pp. 112-125). Elsevier. https://doi.org/10.1016/B978-1-4160-6645-3.00009-8 narcolepsy revisited with special reference to prior wakefulness duration. Sleep, 15(4),

969 Ungurean, G., Barrillot, B., Martinez-Gonzalez, D., Libourel, P.-A., \& Rattenborg, N. C. (2020).

US Department of Commerce, N. (2021, April 10). ESRL Global Monitoring Laboratory. NOAA Solar Calculator. https://gml.noaa.gov/grad/solcalc/

974 van Hees, V. T., Sabia, S., Jones, S. E., Wood, A. R., Anderson, K. N., Kivimäki, M., Frayling, 

accelerometer without sleep diary. Scientific Reports, 8(1), 12975. https://doi.org/10.1038/s41598-018-31266-z Altered ultradian cortisol rhythmicity as a potential neurobiologic substrate for chronic insomnia. Sleep Medicine Reviews, 41, 234-243. https://doi.org/10.1016/j.smrv.2018.03.003

Walch, O., Huang, Y., Forger, D., \& Goldstein, C. (2019). Sleep stage prediction with raw acceleration and photoplethysmography heart rate data derived from a consumer wearable device. Sleep, 42(12), zsz180. https://doi.org/10.1093/sleep/zsz180

Walker, J. M., Glotzbach, S. F., Berger, R. J., \& Heller, H. C. (1977). Sleep and hibernation in

Walker, M. P. (2017). Why we sleep: Unlocking the power of sleep and dreams (First Scribner hardcover edition). Scribner, an imprint of Simon \& Schuster, Inc.

992 Wassmer, T., \& Refinetti, R. (2016). Daily Activity and Nest Occupation Patterns of Fox Squirrels (Sciurus niger) throughout the Year. PLOS ONE, 11(3), e0151249.

Wax, T. M., \& Goodrick, C. L. (1978). Nearness to death and wheelrunning behavior in mice. Experimental Gerontology, 13(3-4), 233-236. https://doi.org/10.1016/05315565(78)90017-7 
998 Webster, J. B., Kripke, D. F., Messin, S., Mullaney, D. J., \& Wyborney, G. (1982). An Activity-

999 Based Sleep Monitor System for Ambulatory Use. Sleep, 5(4), 389-399.

1000 https://doi.org/10.1093/sleep/5.4.389

1001 White, J. A., \& Geluso, K. (2007). Seasonal Differences in Onset of Surface Activity of Ord's Kangaroo Rat ( Dipodomys ordii ). Journal of Mammalogy, 88(1), 234-240.

1003 https://doi.org/10.1644/05-MAMM-A-312R3.1

1004 Williams, C. T., Barnes, B. M., \& Buck, C. L. (2016). Integrating physiology, behavior, and

1005

1006

1007

1008

1009

1010

1011

1012

1013

1014

1015

1016

1017

1018

1019

1020 energetics: Biologging in a free-living arctic hibernator. Comparative Biochemistry and Physiology Part A: Molecular \& Integrative Physiology, 202, 53-62. https://doi.org/10.1016/j.cbpa.2016.04.020

Williams, C. T., Sheriff, M. J., Schmutz, J. A., Kohl, F., Tøien, Ø., Buck, C. L., \& Barnes, B. M. (2011). Data logging of body temperatures provides precise information on phenology of reproductive events in a free-living arctic hibernator. Journal of Comparative Physiology B, 181(8), 1101-1109. https://doi.org/10.1007/s00360-011-0593-z

Wilson, R. P., White, C. R., Quintana, F., Halsey, L. G., Liebsch, N., Martin, G. R., \& Butler, P. J. (2006). Moving towards acceleration for estimates of activity-specific metabolic rate in free-living animals: The case of the cormorant: Activity-specific metabolic rate in freeliving animals. Journal of Animal Ecology, 75(5), 1081-1090. https://doi.org/10.1111/j.1365-2656.2006.01127.x

Wilson, S. (1995). Why We Nap: Evolution, Chronobiology and Functions of Polyphasic and Ultrashort Sleep: (ed. Claudio Stampi), Birkhåuser, Boston, 1992. 275 pp, ISBN 0-81763462-2. Price: SFr 168. Journal of Psychopharmacology, 9(3), 292-292. https://doi.org/10.1177/026988119500900321 
1021 Winnebeck, E. C., Fischer, D., Leise, T., \& Roenneberg, T. (2018). Dynamics and Ultradian

1022 Structure of Human Sleep in Real Life. Current Biology, 28(1), 49-59.e5.

1023 https://doi.org/10.1016/j.cub.2017.11.063

1024 Youngstedt, S. D., Elliott, J. A., \& Kripke, D. F. (2019). Human circadian phase-response curves

1025 for exercise. The Journal of Physiology, 597(8), 2253-2268.

1026 https://doi.org/10.1113/JP276943

1027 Zepelin, H., \& Rechtschaffen, A. (1974). Mammalian Sleep, Longevity, and Energy Metabolism;

1028 pp. 447-470. Brain, Behavior and Evolution, 10(6), 447-470.

1029 Zhang, V. Y., Williams, C. T., Theimer, T. C., \& Buck, C. L. (2019). Reproductive and

1030 Environmental Drivers of Time and Activity Budgets of Striped Skunks. Integrative

1031 Organismal Biology, 1(1), obz013. https://doi.org/10.1093/iob/obz013

1032 Zhang, W., \& Yartsev, M. M. (2019). Correlated Neural Activity across the Brains of Socially

1033 Interacting Bats. Cell, 178(2), 413-428.e22. https://doi.org/10.1016/j.cell.2019.05.023 